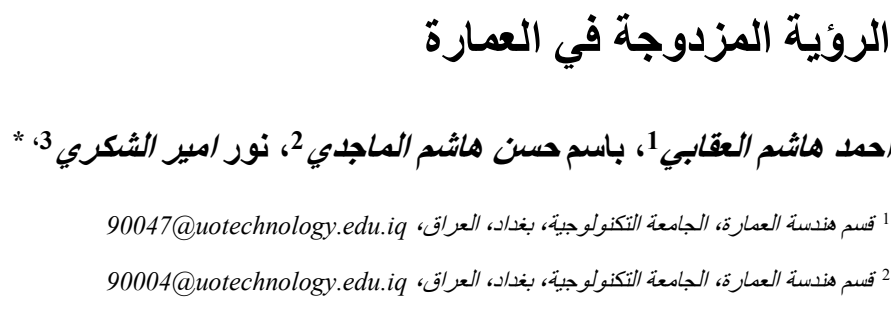

3 90103@student.uotechnology.edu.iq المركز الوطني للاستشارات الهنسية، وزارة الاعمار والإسكان والبلديات العامة، بغداد، العراق،

90103@student.uotechnology.edu.iq الباحث المثل: نور امبر الشكري، *

شر في: 31 كانون الاول 2020

الخلاصة ـ تعد العمارة ونتاجاتها من أكثر الحقول المعرفية اتصالا بالبشر والحياة اليومية ولكون النتاج المعماري بمثل رؤية المعماري

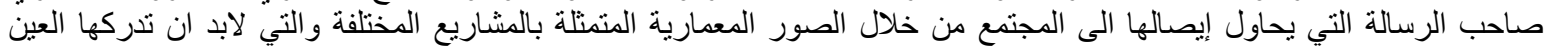

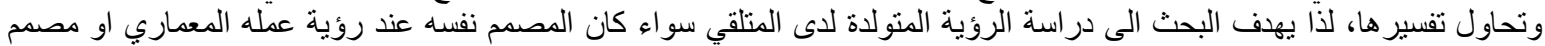

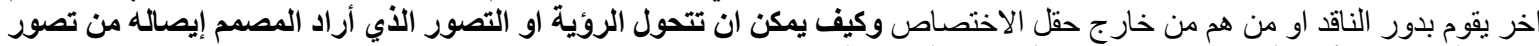

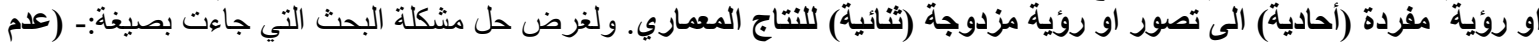

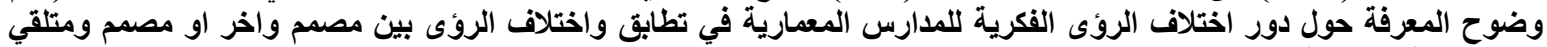

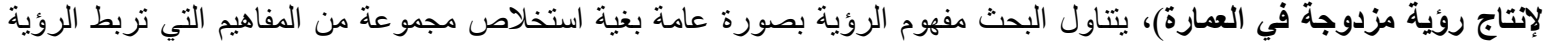

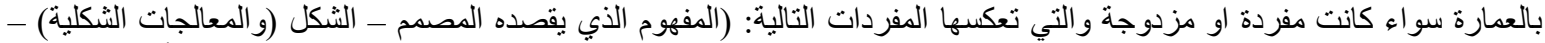

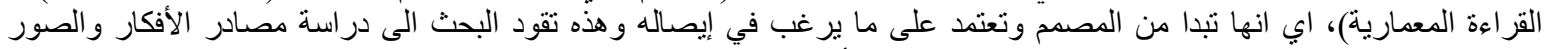

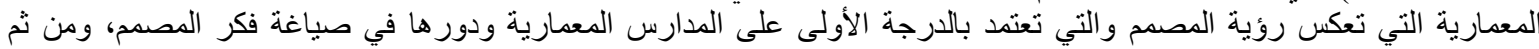

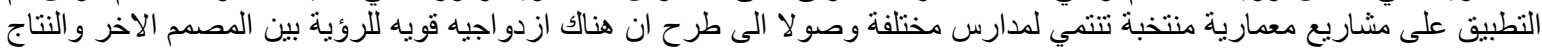
مقابل ازدو اجيه جزئيه للارؤية بين المصدم و النتاج وبين المتلقي وارئن النتاج.

عرض الطرح المعرفي المعماري العام عن المفهوم الاساسي

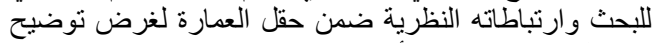

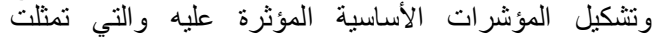

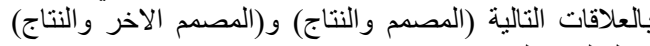
و(المتلقي و النتاج).

تطبيق المؤشرات الأساسية التي تم تشكبلها سلفا على عينات

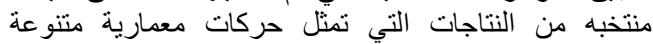
ومناقثنه وتحليل نتائج ذلك ألنطبيق.

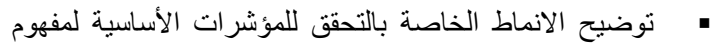

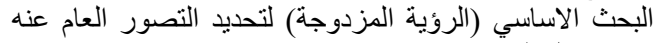
ضمن حقل العمارة.

$$
\begin{aligned}
& \text { 2. الجزء الأول: الطرح النظري العام } \\
& 2.1 \\
& 2.1 .1
\end{aligned}
$$

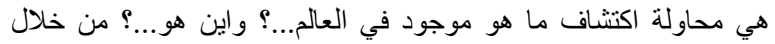

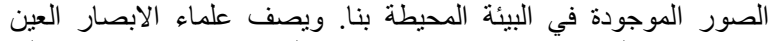

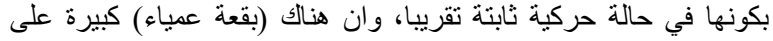

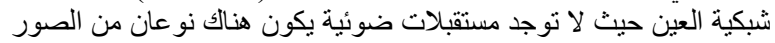

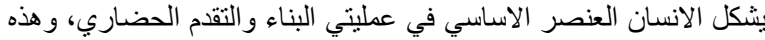

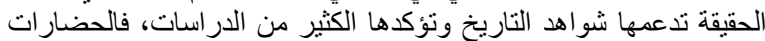

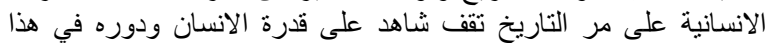

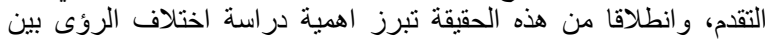

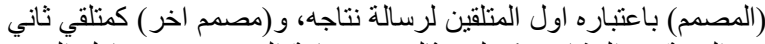

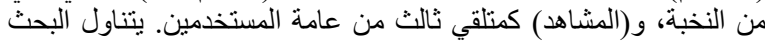

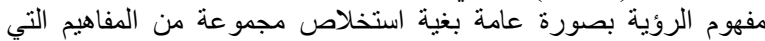

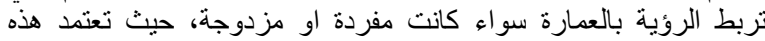

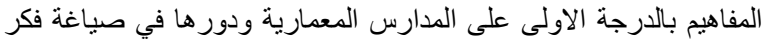

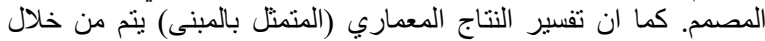

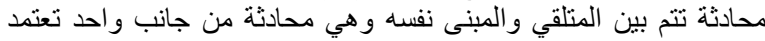

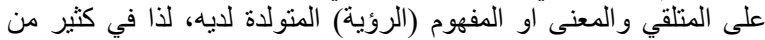

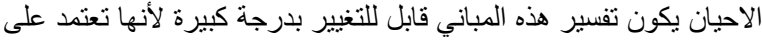

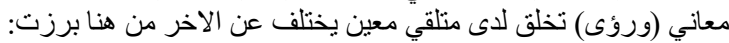

مشكلة البحث التي جاءت بصيغة: - (ضعف المعرفة حول توضيح مفهوم الروئه المزدوجه في التيارات المعماريه المختلفه).

اما هدف البحث فقد تمثل بتوضيح المعرفة حول مفهوم الرؤيه المزدوجه في التيارات المعماريه المختلفه.

اما فرضية البحث فقد تمثلت بان هناك اختلاف في الرؤى الفكرية

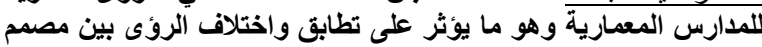
واخر او مصمم ومتلقي لإنتاج روئية مزدوجة في في العمارة. 
بالاعتماد على الطرح السابق يمكن تعريف الروئة في العمارة بانها:

التفاعل البصري والفكري بين الصور المعمارية والتي تمثل الفكرة

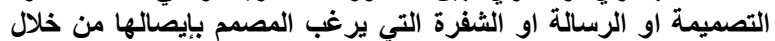

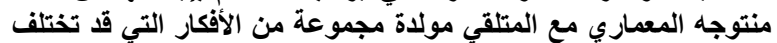

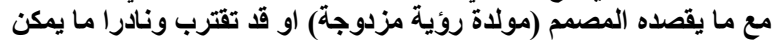

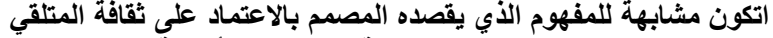
والصورة التي ينظر اليها (مولدة الروية الئه المفردة او الأحادية).

$$
\text { الرؤية ضصن الإطار التصميسي العام }
$$

تمتلك العمارة مستويين من التعبير، الاول: التعبير اللفظي (الثفهي)

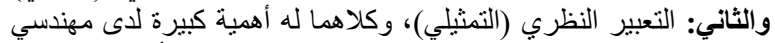

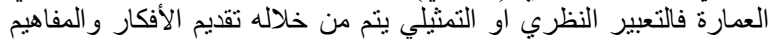

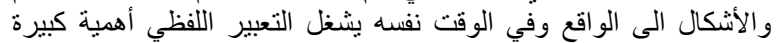

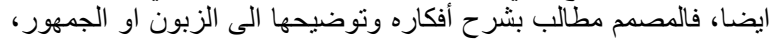

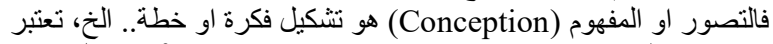

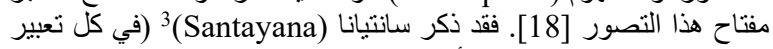

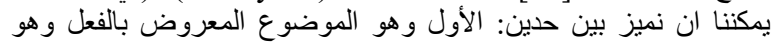

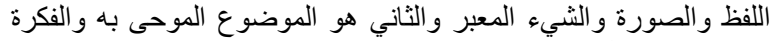

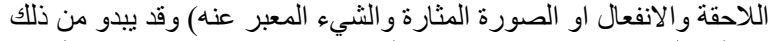

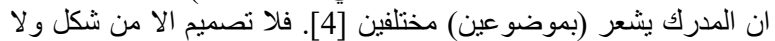

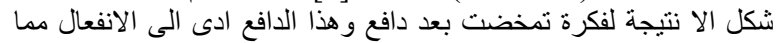

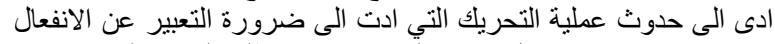

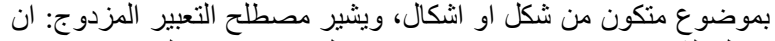

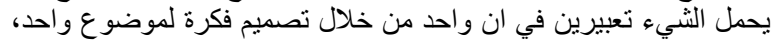

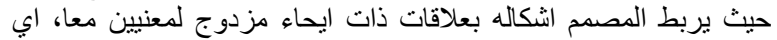
يجمع فكرتين لتصميم واحد. وبذلك يتلقى المشاهد ازدوات اجية (ثنائية) في

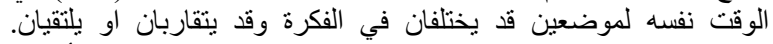

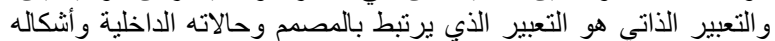

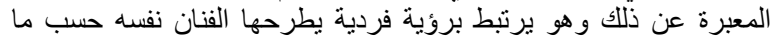

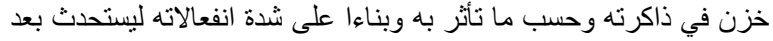
ذلك تعبيره عن حالته تللك ليتسلمها المتلقي [1] فئرة

$$
\text { الرؤية و النتاج المعماري (المتلقي و النتاج) }
$$

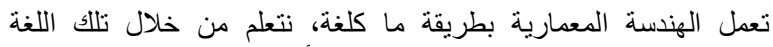

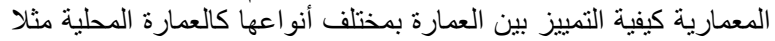

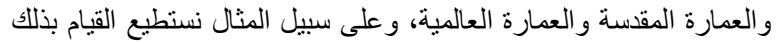

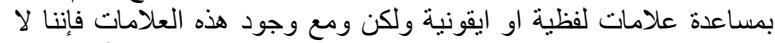

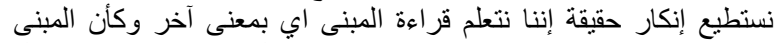

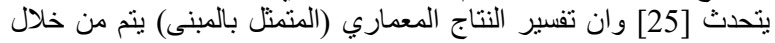

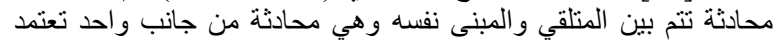

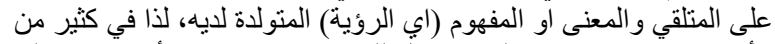

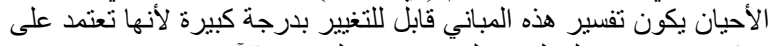
معاني (ورؤى) تخلق لاى متلقي معين يختلف عن الآخر [15].

سنة (Estetika i teorija informacije - Aesthetics and information theory)

3ورج سانتيانا George Santavana

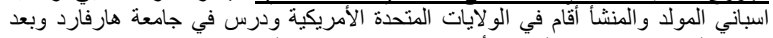

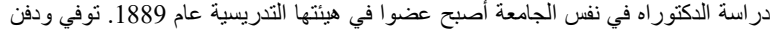

في المقبرة الاسبانيةً في روما سنة 1952 [3].

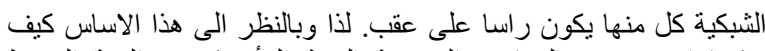

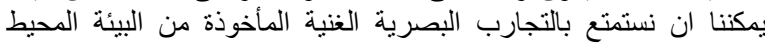

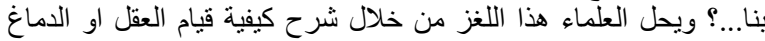

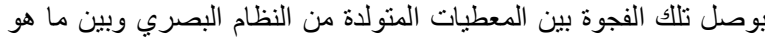

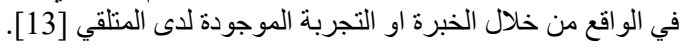

$$
\text { 2.1.2 الرؤية فلسفيا }
$$

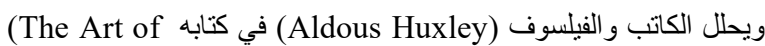

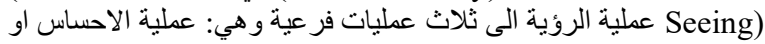

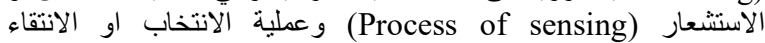
Process of و وعلية الادر الك او التصور الأنساء (Process of selecting) Perceiving

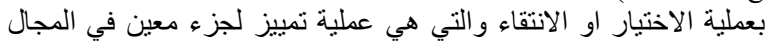

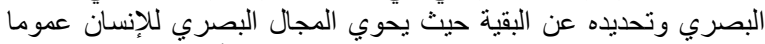

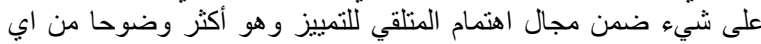

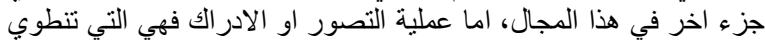

على الاعتر اف والاقرار بالمواد (او الصور ) المحسوسة والئه المختارة [12].

$$
\text { 2.1.3 الرؤية في العمل الفني }
$$

يتحدث (د. منصور نعمان) في مقالة لله بعنوان (الرؤية والتعبير في الفن الفنان

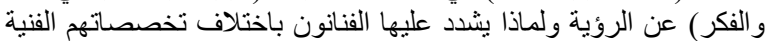

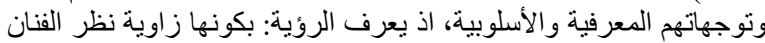

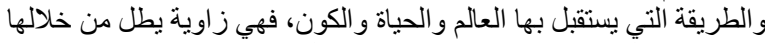

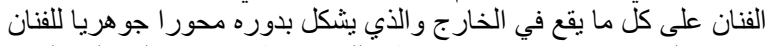

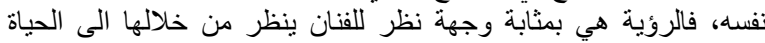

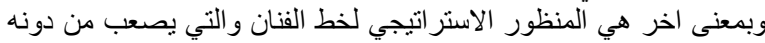

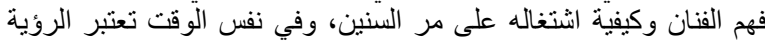

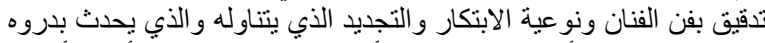

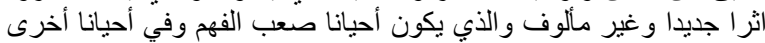

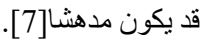

$$
\text { 2.1.4 الرؤية في العمارة }
$$

بواسطة طرق الاظهار المختلفة، حيث يوضح المعمار (Robin Evans)

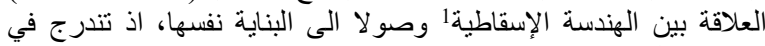

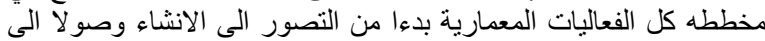

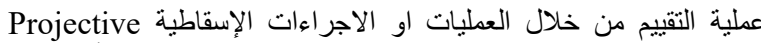
ذهن (Transactions)

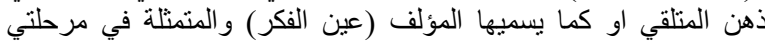

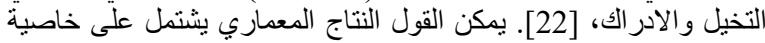

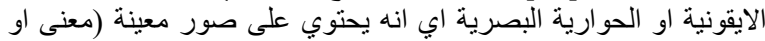

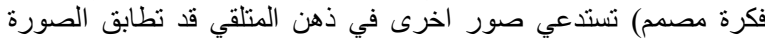

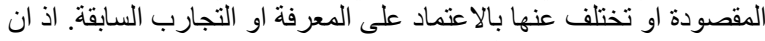

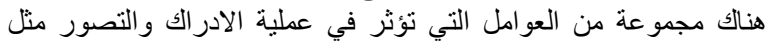

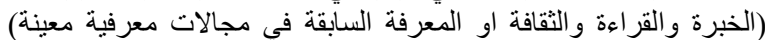

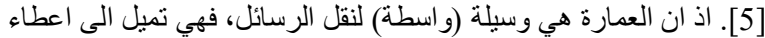

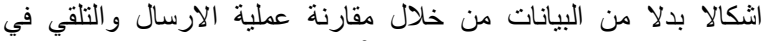
تكنولوجيا الاتصالات مع العمارة [39]2.

1الهندسة الإسقاطية projective geometry: نظام جميل ومعقد من المقتر حات الهندسية، تم تطويره تاريخيا من الهندسة الاقليدية، تُعنى الهندسة الإسقاطية بدر اسلة الخصائص الهنات الهندسية التي يتم الحفاظ عليها خلال عملية الاسقاط المركز للنقاط أو الخطوط الخختلفة [21].

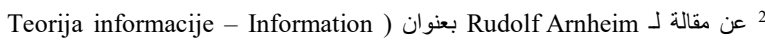
في اللغة الكرواتية، ص 81 ضمن كتاب لـ Umberto Eko بعنوان 
التعددية الذي أصبح سمة مميزة للغة عمارة ما بعد الحداثة، حيث تكون

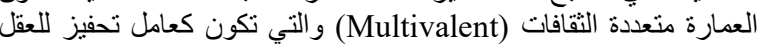

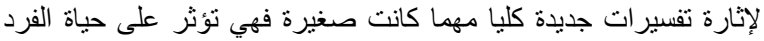

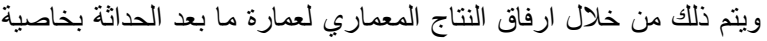

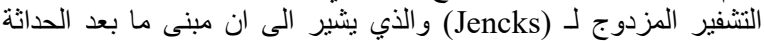

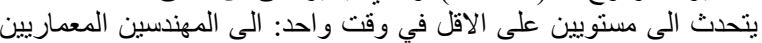

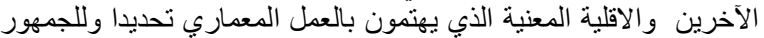

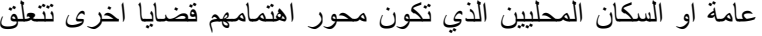

بالر احة و المباني التقليدية وطريقة الحياة [16] لـ العين

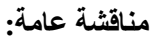

يتضح مما سبق ان الروئة في العمارة هي هدف او رسالة لمصمم يتم

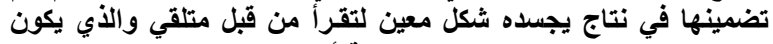

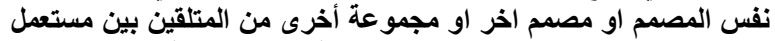

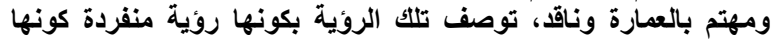

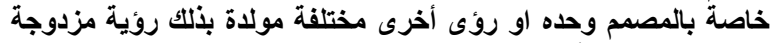

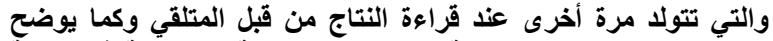

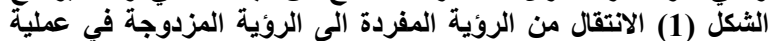

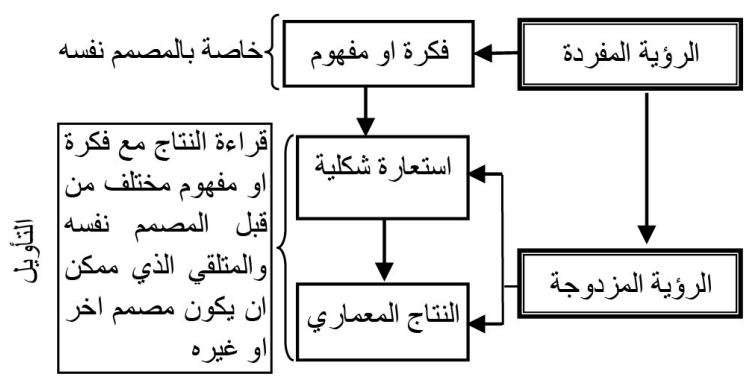

الثكل 1: الانتقال من الرؤية المفردة الى الرؤية المزدوجة في عملية التصميم / المصدر (الباحثون) الرونة الترونة

لذا يمكن القول ان الروئة المزدوجة هو ان يرى النتاج المعماري الذي مئي

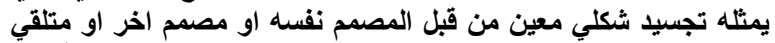

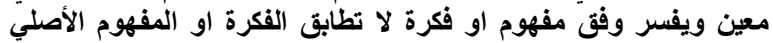

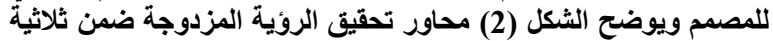
(المصم - المتلقي - النتاج المعماري).

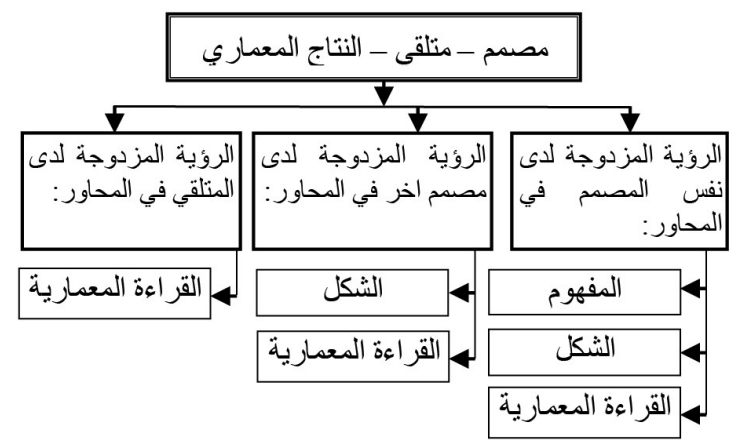

الثكل 2: محاور تحقيق الرؤية المزدوجة ضمن ثلاثية (المصمم - المتلقي - النتاج المعماري) / الرؤية المصدر (الباحثون)

$$
\text { 2.2.3 }
$$

ان مصطلح الحوارية البصرية او (الايقونية) وهو مصطلح استعمله 4 (Bruce G. Shapiro)

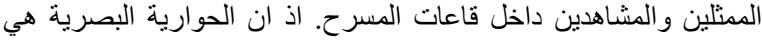

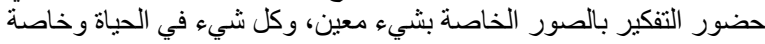

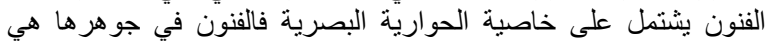

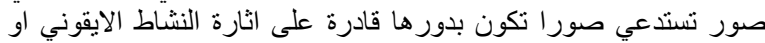

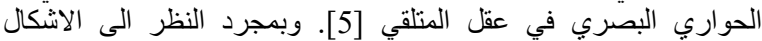

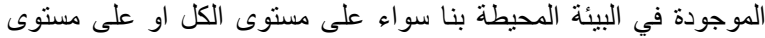

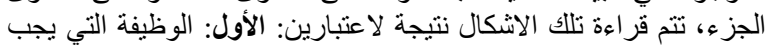

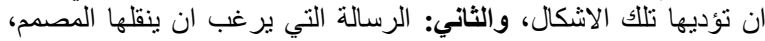

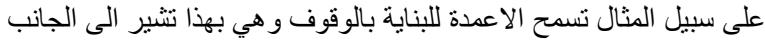

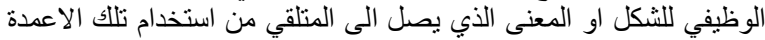

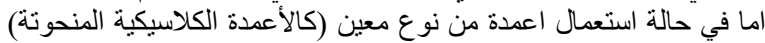

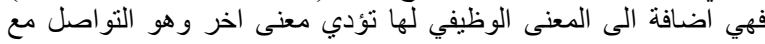
المثل الرومانية او اليونانية القديمة في حين تثير تئير الاعمدة النحيلة الانيقة

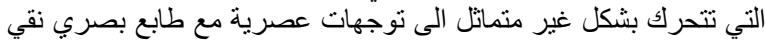

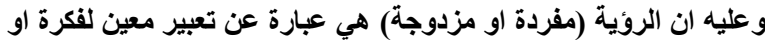

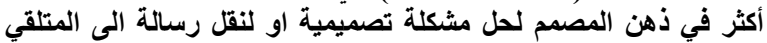

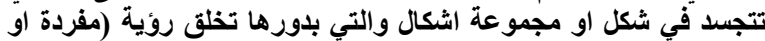

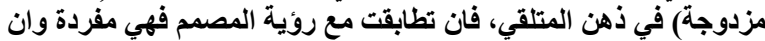

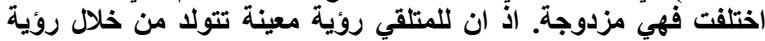

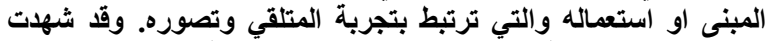

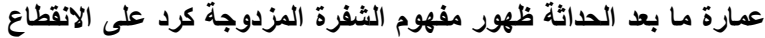

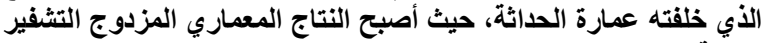
وسيلة لتحقيق التواصل بين الماضي والحداض أصبر.

$$
\text { الثفرة المزدوجة في العمارة وقر اعة النتاج }
$$

بصف (Jencks) 5 عمارة ما بعد الحداثة بانها (تشفير مزدوج) تقريبا اي

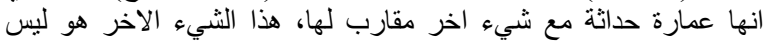

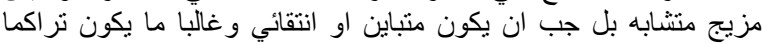

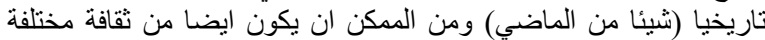

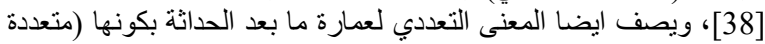

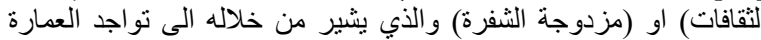

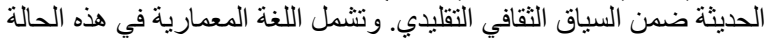

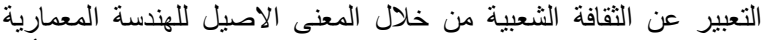

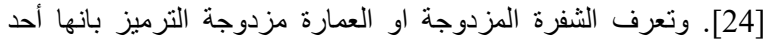

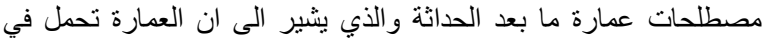

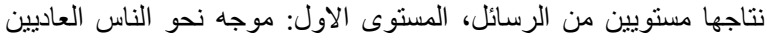

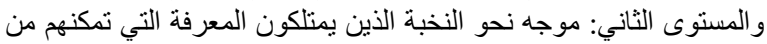

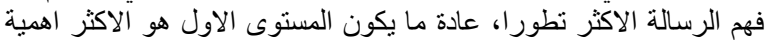

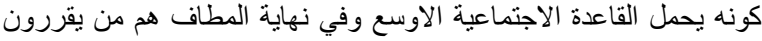

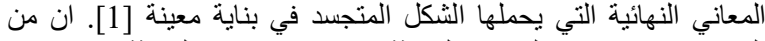
المفارقات بين نتاج العمارة الحديثة وعمارة ما بعد الحداثة هو مفهوم

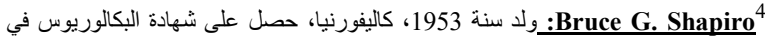

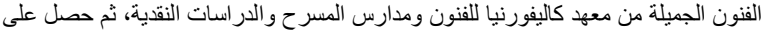

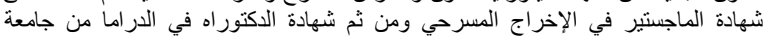
Queensland

Charles Alexander Jencks 5

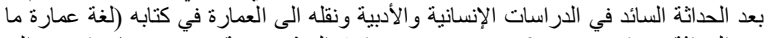

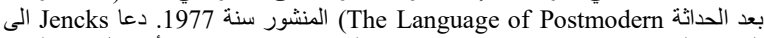
التشفير المزدوج double) (codification والذي يعبر عن عمارة تأخذ كل من النخبة و العامة بعين الاعتبار [23] 


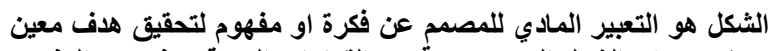

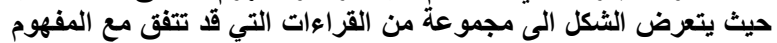

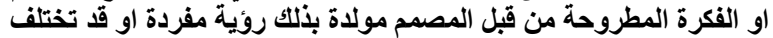
مولدة روئة مزدوجة.

$$
2.3 .3
$$

يتمثل التعريف الأساسي للقراءة (Read) في كونها النظر الى معنى ألى اعتى

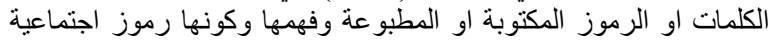

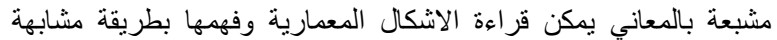

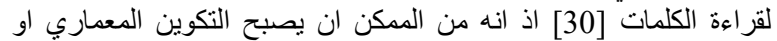

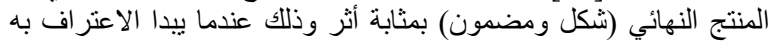

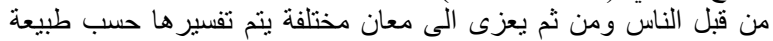

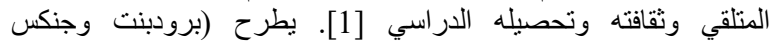

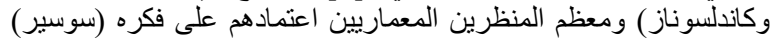

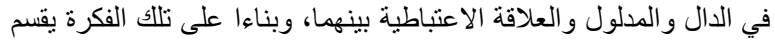

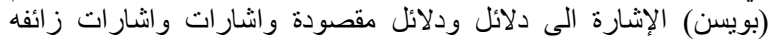

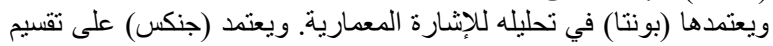

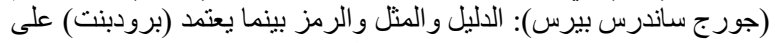

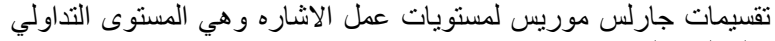

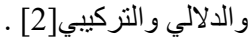

فالقراعة المعمارية هي التفاعل الذهني بين المتلقي والنتاج المعماري

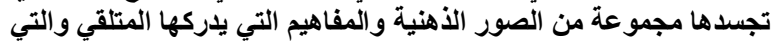

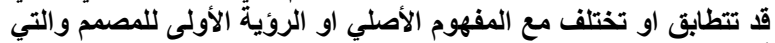

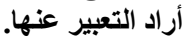

يوضح الثكل (3) الروية المزدوجة في العمارة من خلال توضيح العلاقات

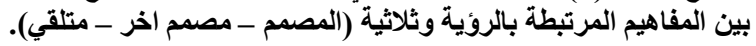

محاور تحقيق الرؤية المزدوجة (المفا هيم المعدارية المرتبطة

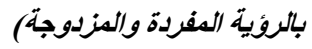

لأجل توضيح المؤشر ات الأساسية للرؤية التي يتعامل بها المصمم والتي تم

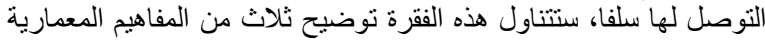

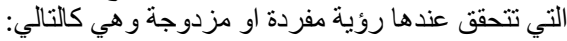

$$
\text { 2.3.1 }
$$

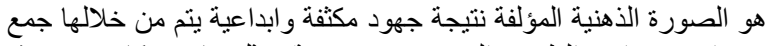

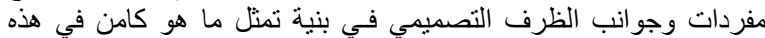

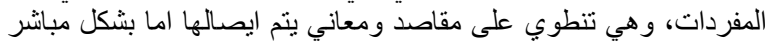

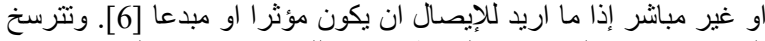

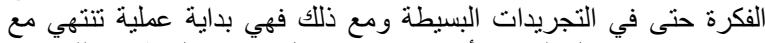

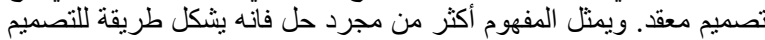
في مشكلة تصميمة معينة حيث يكون المفهوم هو بداية عملية التصميم

.[14]

يمثل المفهوم او الفكرة رؤية محدده يرغب المصمم بإيصالها والتعبير عنها في نتاجه المعماري بغية تحقيق هدف معين.

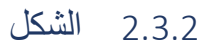

يمثل الثكل المادة البصرية التي تتلقاها العين و الذي ينظم بطريقة معينة

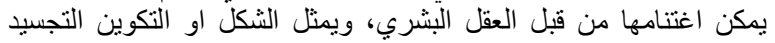

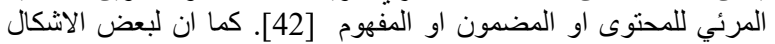

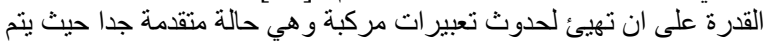

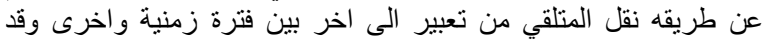

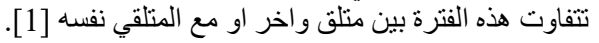

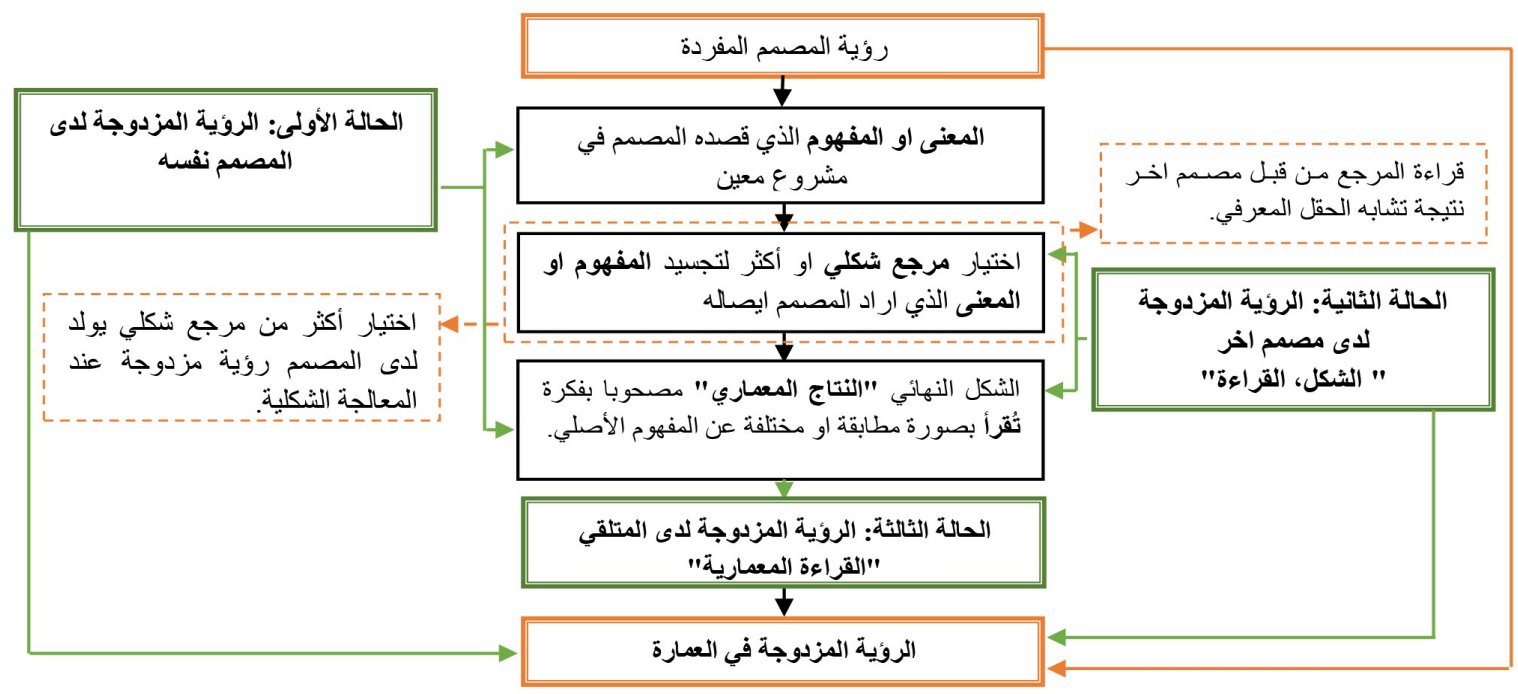

الثكل 3: محاور تحقيق الرؤية المزدوجة في العمارة ضمن ثلاثية (المصمم ـ مصمم ثان ـ المتلقي) و علاقتها بالمؤشرات الثلاثة (المفهوم ـ الثكل القر اءة المعمارية) / المصدر (الباحثون)

$$
\text { و } 2.4 .1
$$

الرؤية المزدوجة لاى المصمم نفسه هو ان يظهر النتاج المعماري النهائي

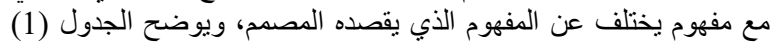

\section{4}

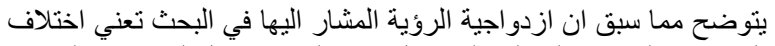

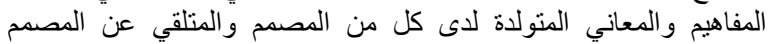

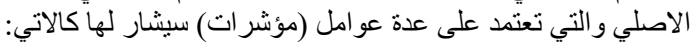


والثكل (4) المؤشرات الاساسية التي تتولد فيها رؤية مزدوجة لدى المصمح.

الجدول 1: الرؤية المزدوجة لدى نفس المصمم / المصدر (الباحثون)

\begin{tabular}{|c|c|}
\hline تعريف حالة الوصف & المؤشر \\
\hline 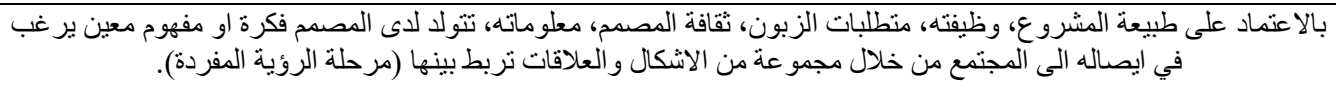 & ولادة واختيار \\
\hline 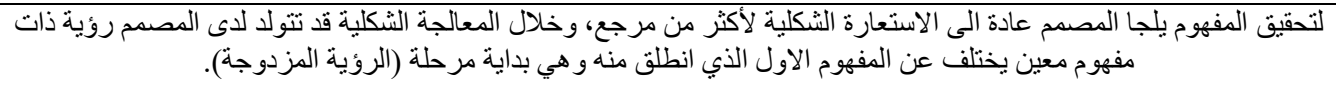 & (المادي للمفهوم او التمثيل \\
\hline 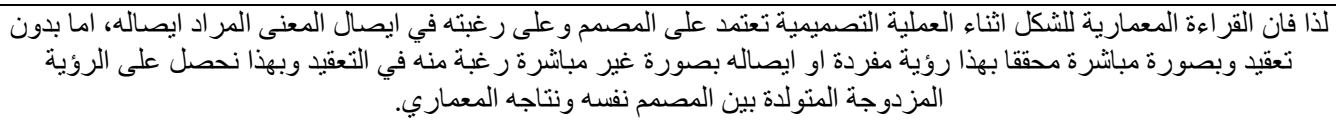 & القراعة المعمارية \\
\hline
\end{tabular}

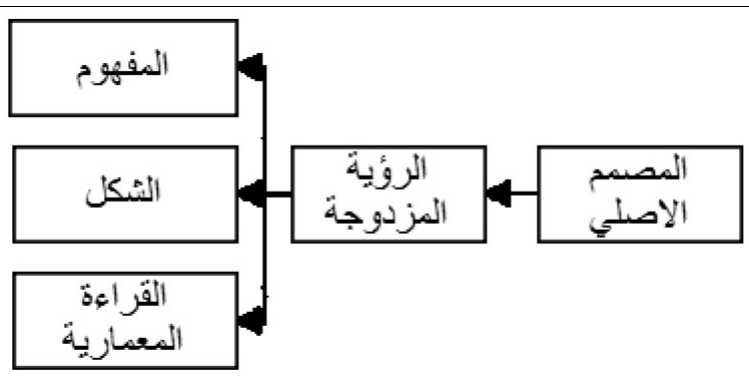

الثكل 4: الرؤية المزدوجة لدى نفس المصمم / المصدر (الباحثون)

فالسؤال المطروح هو هل يمكن ان نحصل على رؤية مزدوجة عند تشابه

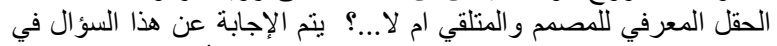

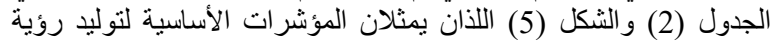
مزدوجة لدى مصمم اخر.
الرؤية المزدوجة لاى مصمم اخر (مصمم اخر

2.4 .2

و النتاج)

المتلقي هنا وقارئ الثكل المعماري هو مصمم اخر يقوم بدور الناقد مثلا

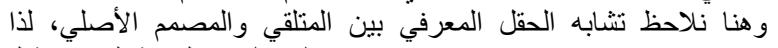
الجدول 2: الرؤية المزدوجة لاصى مصمم اخر / المصدر (الباحثون)

\begin{tabular}{|c|c|}
\hline تعريف حالة الوصف & المؤشر \\
\hline جانب ذاتي خاص بالمصمم نفسه & المفهوم \\
\hline 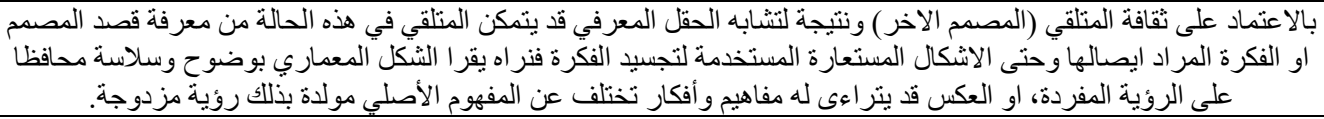 & (الثكل) او التمثيل \\
\hline 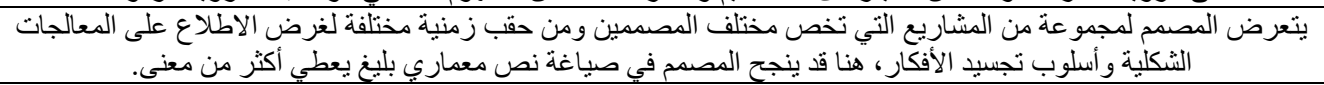 & القراعة المعمارية \\
\hline
\end{tabular}

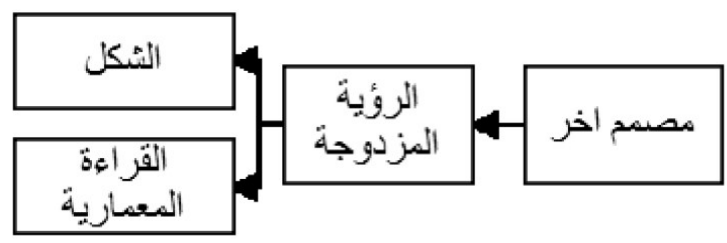

الثكل 5: الرؤية المزدوجة لدى مصمم اخر / المصدر (الباحثّون)

و على ثقافتهم العامة و الثخصية. بالإضافة الى التجربة الثخصية التي تمكن

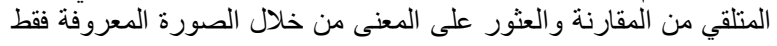
[34]. يوضنح

الجدول (3) والثكل (6) المؤشر الخاص بالرؤية المزدوجة المتولدة لدى

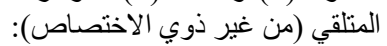

$$
\begin{aligned}
& 2.4 .3 \text { الرؤية المزدوجة لدى المتلقي (من خارج حقل } \\
& \text { العمارة) (المتلقي و النتاج): }
\end{aligned}
$$

ان اللغة التي يعتمدها المتلقي لحل (فلك الثفرة) الموجودة في القطع

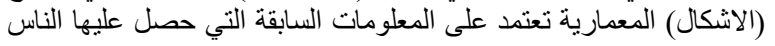


الجدول 3: الرؤية المزدوجة لدى المتلقي (من خارج حقل العمارة) / المصدر (الباحثون)

\begin{tabular}{|c|c|}
\hline تعريف حالة الوصف & المؤشر \\
\hline جانب ذاتي خاص بالمصمم نفسـ & المفهوم \\
\hline خاص بذوي الاختصاص & (المادي للمفهوم او التمثيل \\
\hline 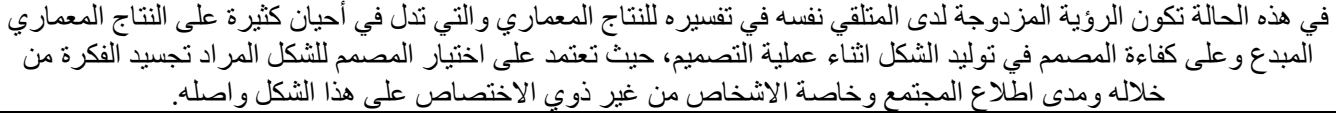 & القراءة المعمارية \\
\hline
\end{tabular}

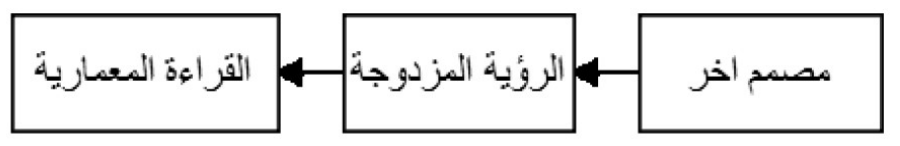

الثكل 6: الرؤية المزدوجة لدى المتلقي / المصدر الباحثون

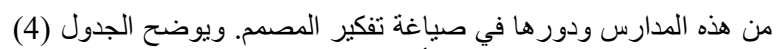

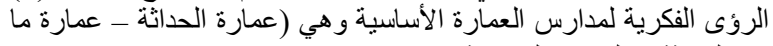
بعد الحداثة ـ العمارة التفكيكية).

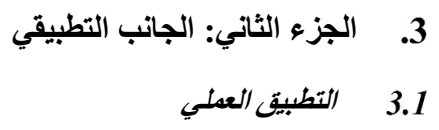 \\ 3.1
}

3.1 .1

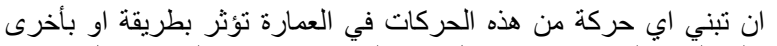
الجدول 4: الرؤى الفكرية للمدارس الفدسة المعمارية / المصدر (الباحثون)

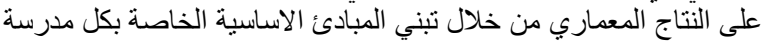

\begin{tabular}{|c|c|c|}
\hline الروئية الفكرية & & المدرسة المعمارية \\
\hline 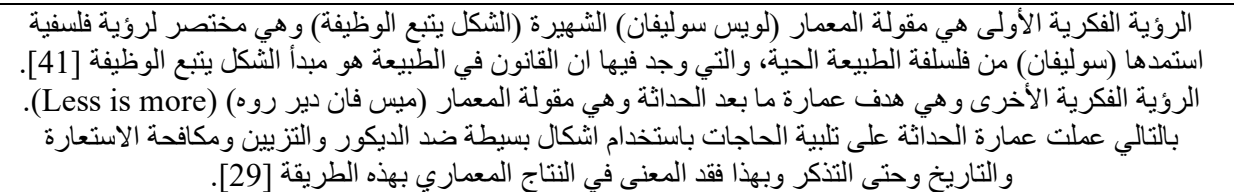 & - & عمارة الحداثة \\
\hline 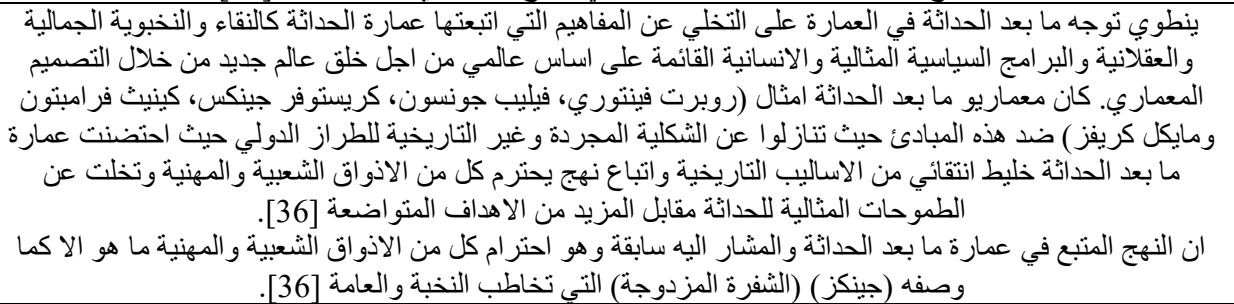 & - & عمارة مـا بعد \\
\hline 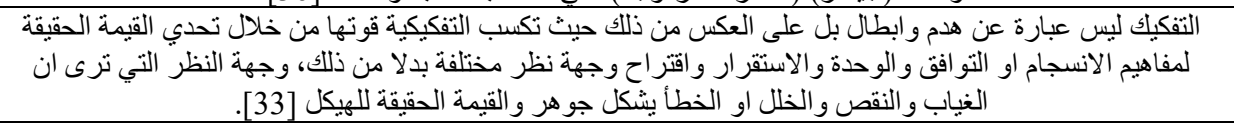 & 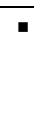 & العمارة التفكيكية \\
\hline
\end{tabular}

يوضح الجدول (5) دور تلك المدارس المعمارية في تحقى الرؤية المزدوجة الفوابة

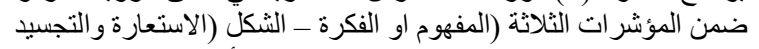

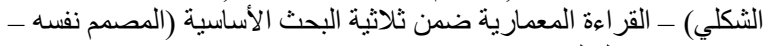

مصمح اخر - المنلقي):

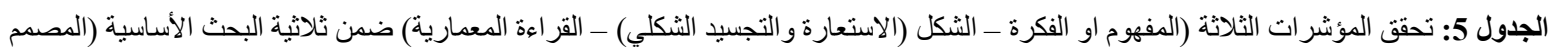

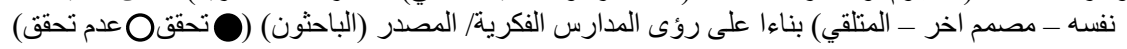

\begin{tabular}{|c|c|c|c|c|c|c|c|c|c|}
\hline \multicolumn{3}{|c|}{ المتلقي } & \multicolumn{3}{|c|}{ مصمم اخر } & \multicolumn{3}{|c|}{ المصمم نفسه } & ثلاثية البحث \\
\hline \multicolumn{3}{|c|}{ المؤشرات } & \multicolumn{3}{|c|}{ المؤشرات } & \multicolumn{3}{|c|}{ المؤشرات } & \\
\hline القراءة & الشكل & المفهوم & القراعة & الثكل & المفهوم & القراءة & الثكل & المفهوم & \\
\hline
\end{tabular}




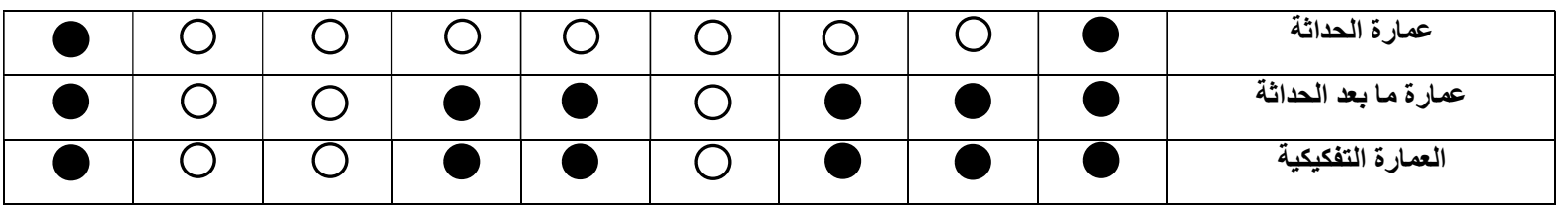

مناقثة عامة:

\section{1 .2}

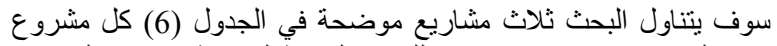

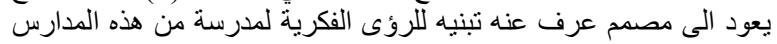

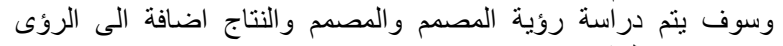

$$
\text { الاخرى عن المشروع. }
$$

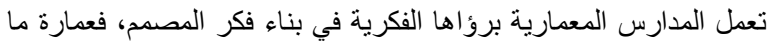

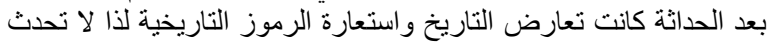

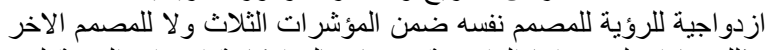

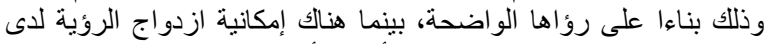

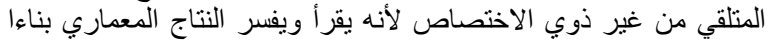

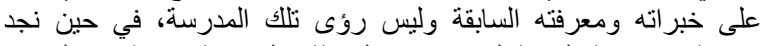

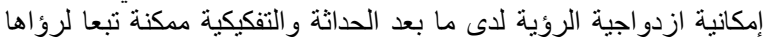

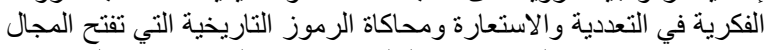

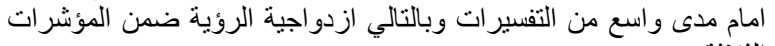

الثلاثة.

الجدول 6: المشاريع الممثلة للمدارس المعمارية / المصدر (الباحثون)

\begin{tabular}{|c|c|c|c|c|}
\hline \multirow{2}{*}{ معلومات عن المشروع } & \multicolumn{3}{|c|}{ المدرسة المعمارية } & \multirow{2}{*}{ اسم المشروع } \\
\hline & العمارة التفكيكية & عمارة ما بعد الحداثة & عمارة الحداثة & \\
\hline 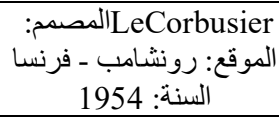 & & & & كنيسة نوتردام \\
\hline 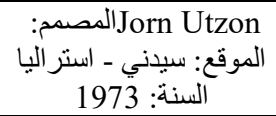 & & & & دار الاوبرا في سيدني \\
\hline $\begin{array}{l}\text { الموقع: بلباو - اسبانيا Frank Gehry } \\
\text { المصم:: } 1997 \text { السنة: }\end{array}$ & & & & متحف غوغنهايم \\
\hline & & \multicolumn{3}{|c|}{ 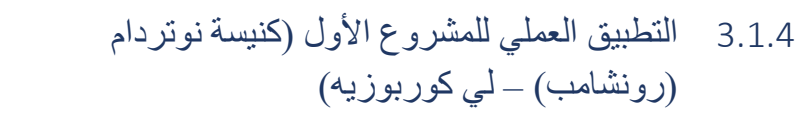 } \\
\hline & & مّ - مصح في الشكل (7) & ثلاثية البحث الأو & و والمتضحن الجدول (7) التطبيل \\
\hline
\end{tabular}

الجدول 7: تحليل المشروع الاول ضمن ثلاثية: مصمم-مصمم اخر-متلقي/المصدر (الباحثون)

\begin{tabular}{|c|c|}
\hline \multicolumn{2}{|l|}{ المشروو الاول: كنيسة نوتردام (رونشامب) - لي كوربوزيه } \\
\hline الرؤية & ثثلاثية البحث \\
\hline 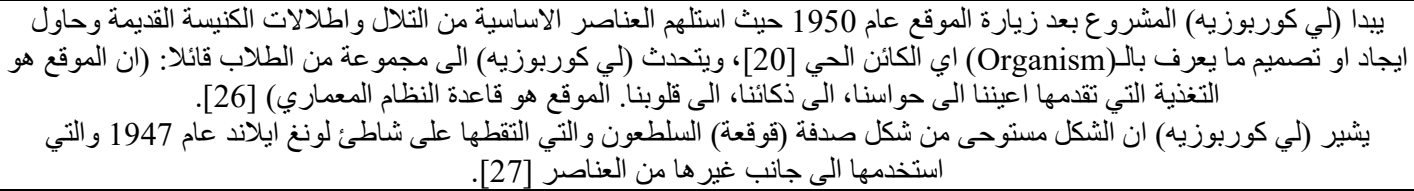 & بين المصدم \\
\hline
\end{tabular}




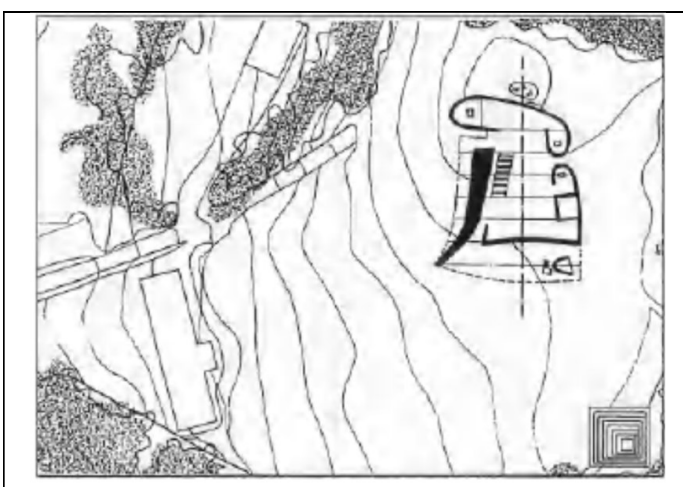

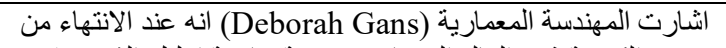

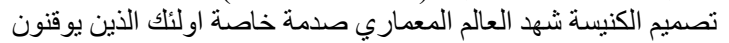

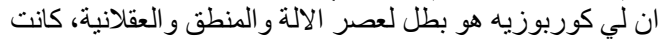

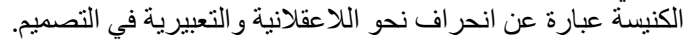

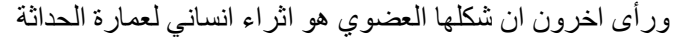

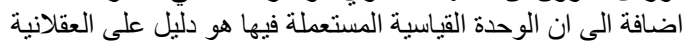

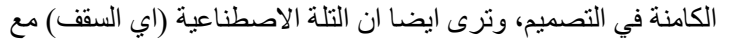

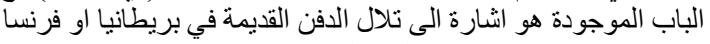

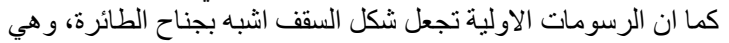

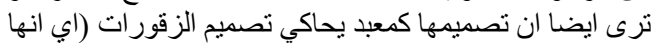

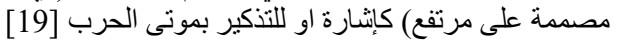

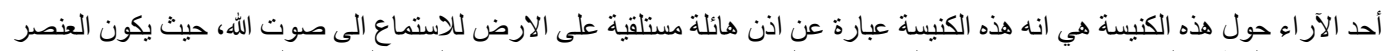
الوظيفي للاستماع بارز الكي وان هذه الفتحات في الواجهات هي عبارة عن دراسة كانلة كاملة في التركيب الموسيقي [27].

مصمم اخر و النتاج

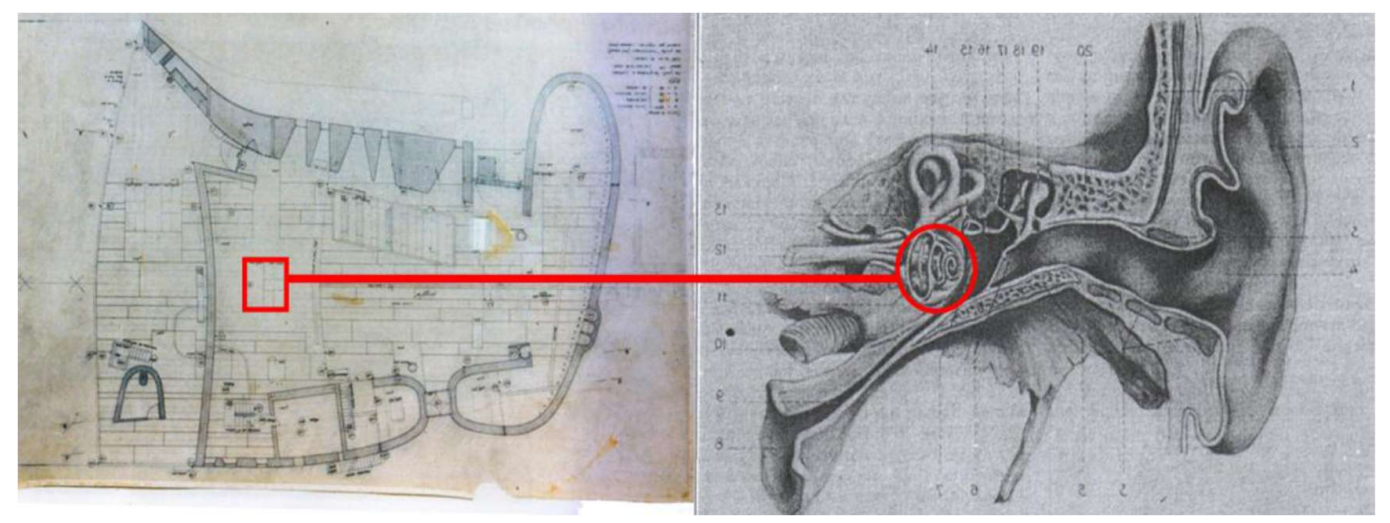

يشير الموقع الإكتروني (The guardian) ان سقف الكنيسة تمت مقارنته مع خمار الراهبة (أحد مستعملي وزائري المشروع) [48].
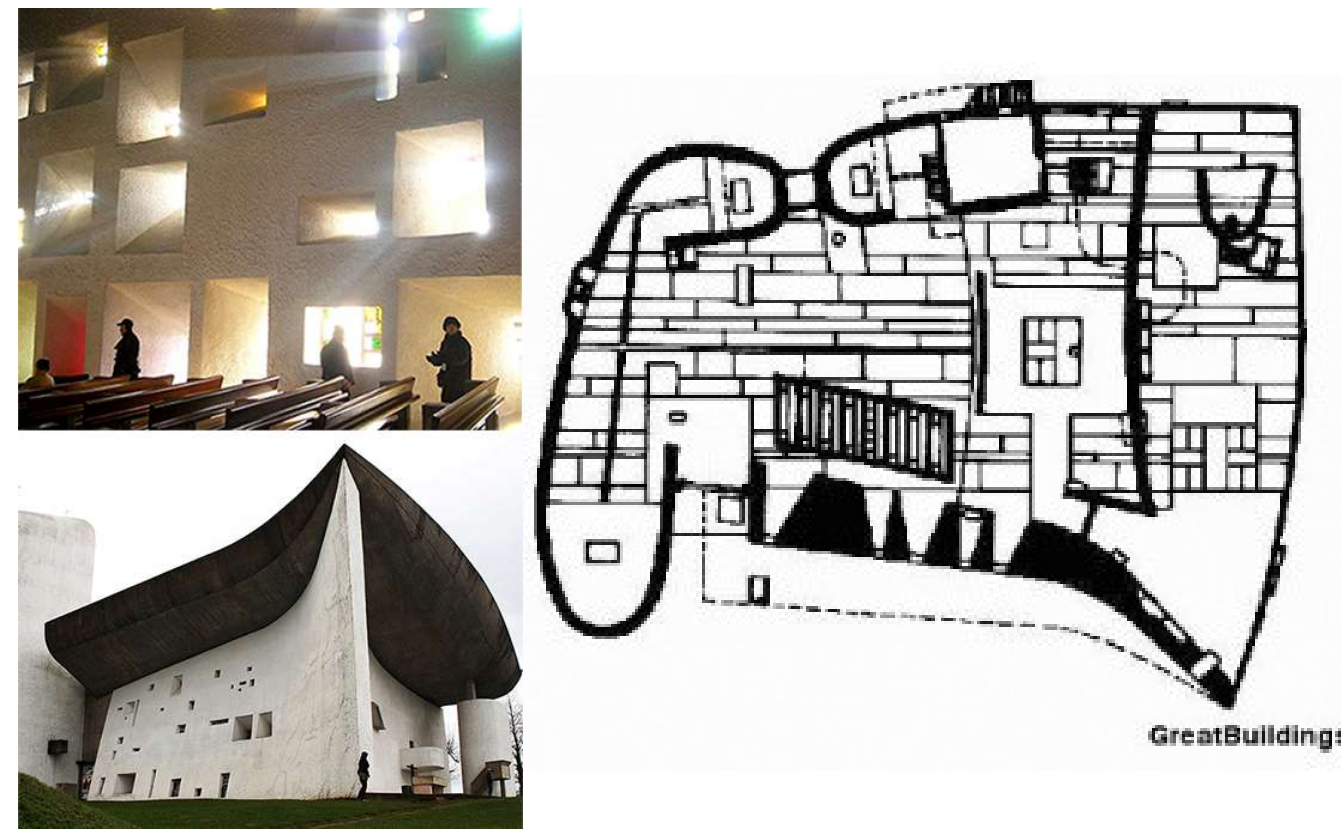

الثكل 7: كنيسة نوتردام (رونشامب) - لي كوربوزيه [43] 
يوضح الجدول (8) التطبيق العملي للمشروع الثناني الموضح في الثكل (8) (لمثن

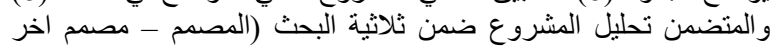
و المتلقي).

$$
\text { سبيني - التطبيث العملي للمشروع الثاني (دار الاوبر ا في }
$$

\begin{tabular}{|c|c|c|}
\hline \multicolumn{3}{|l|}{ Jorn Utzon المشروع الثاني: دار الاوبرا في سيدني - يورن اوتزون } \\
\hline (الروئة & & ثلاثية البحث \\
\hline 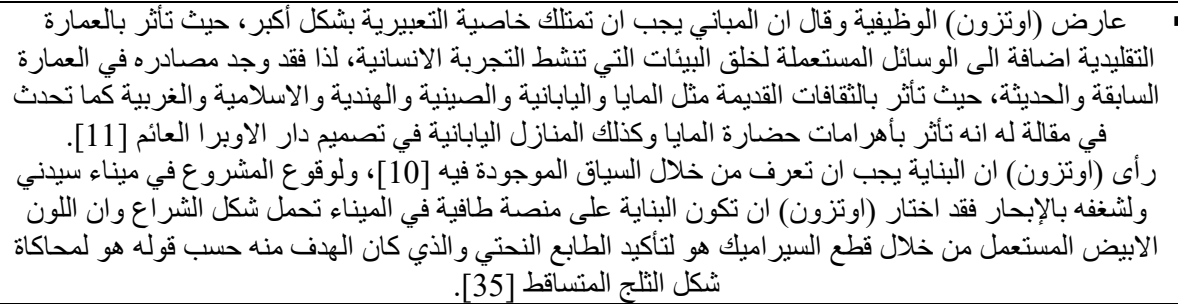 & - & 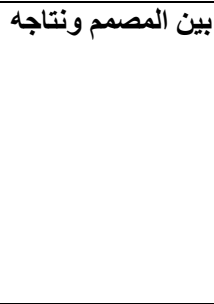 \\
\hline 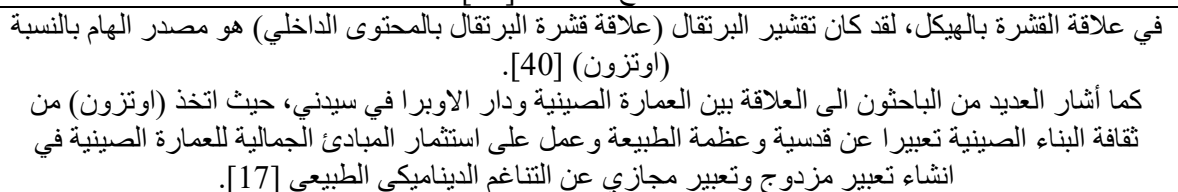 & . & مصمم اخر والنتاج \\
\hline 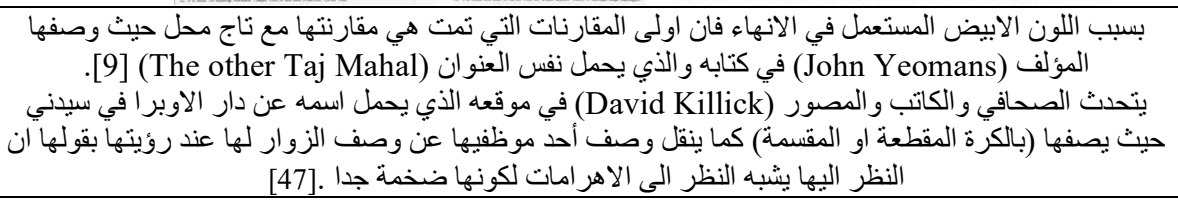 & I & المتلقي والنتاج \\
\hline
\end{tabular}

الجدول 8: تحليل المشروع الثاني ضمن ثلاثية: مصمم-مصمم اخر-متلقي/المصدر (الباحثون)
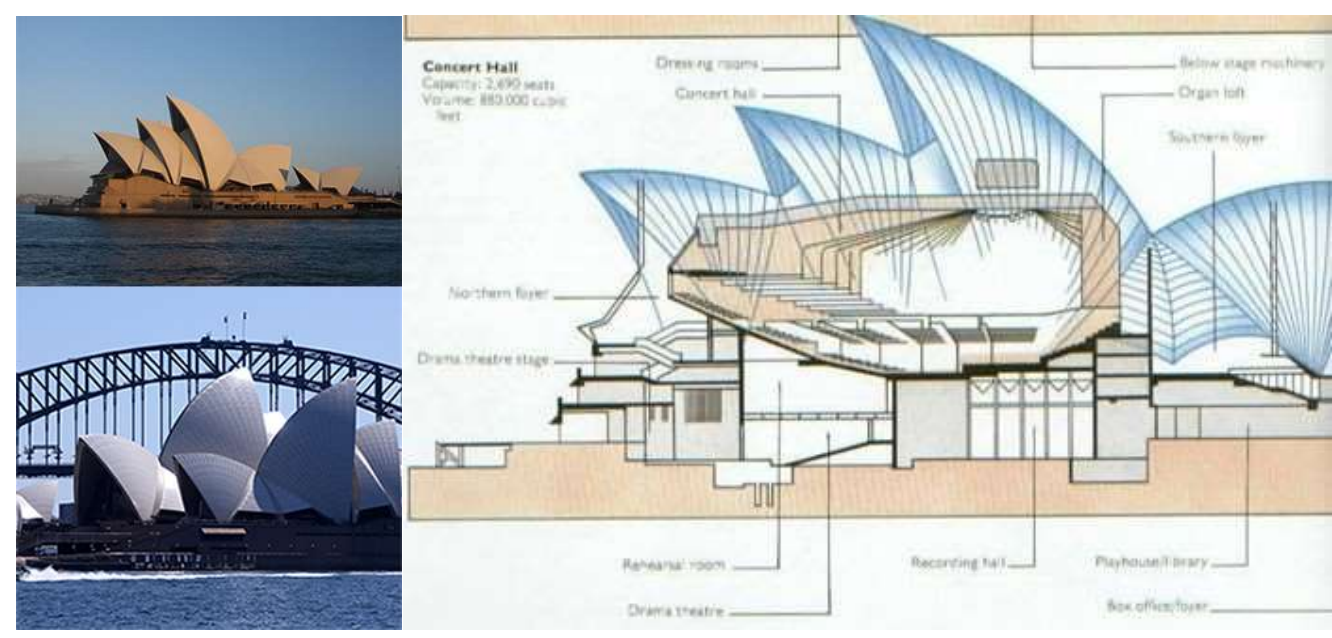

الثكل 8: دار الاوبرا في سيدني - يورن اوتزون [44] 
يوضح الجدول (9) التطبيق العملي للمشروع الثنالث الموضح في الثنكل

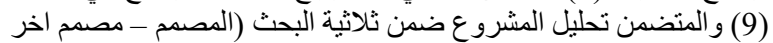

والمنلقي).

$$
\text { فر انلك جيري) التطلي للمشروع الثالث (متحف غو غنهايم - }
$$

\begin{tabular}{|c|c|c|}
\hline \multicolumn{3}{|l|}{ المشروع الثالث: متحف غوغنهايم ـ فرانك جيري } \\
\hline الروية & & ثثلاثية البحث \\
\hline 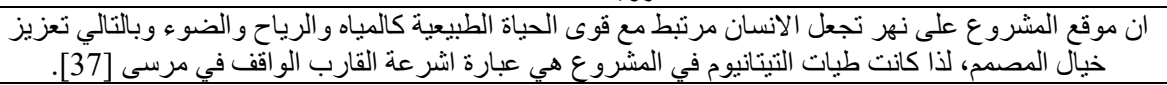 & - & بين المصمم ونتاجه \\
\hline 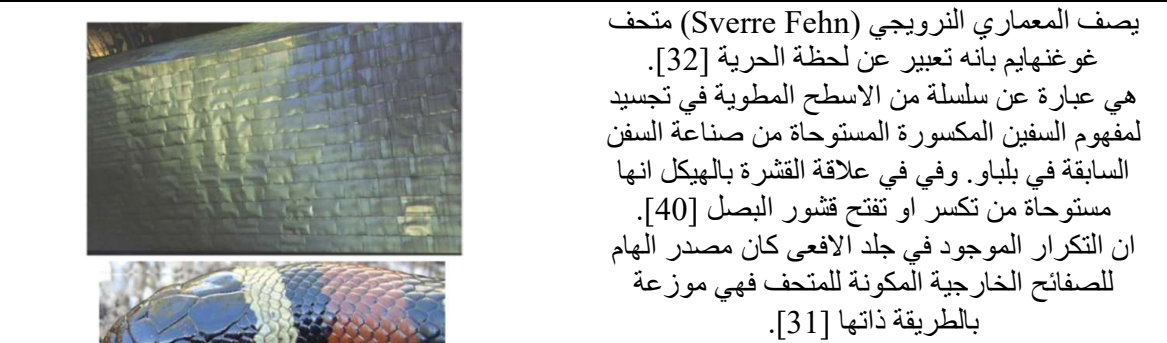 & - & 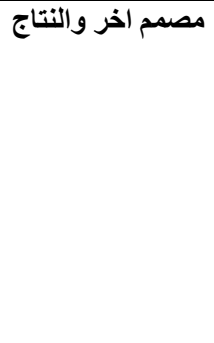 \\
\hline 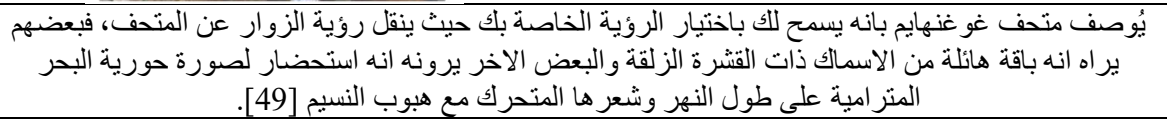 & - & المتلقي والنتاج \\
\hline
\end{tabular}

الجدول 9: تحليل المشروع الثالث ضمن ثلاثية: مصمم-مصمم اخر -منلقي/المصدر (الباحثون)
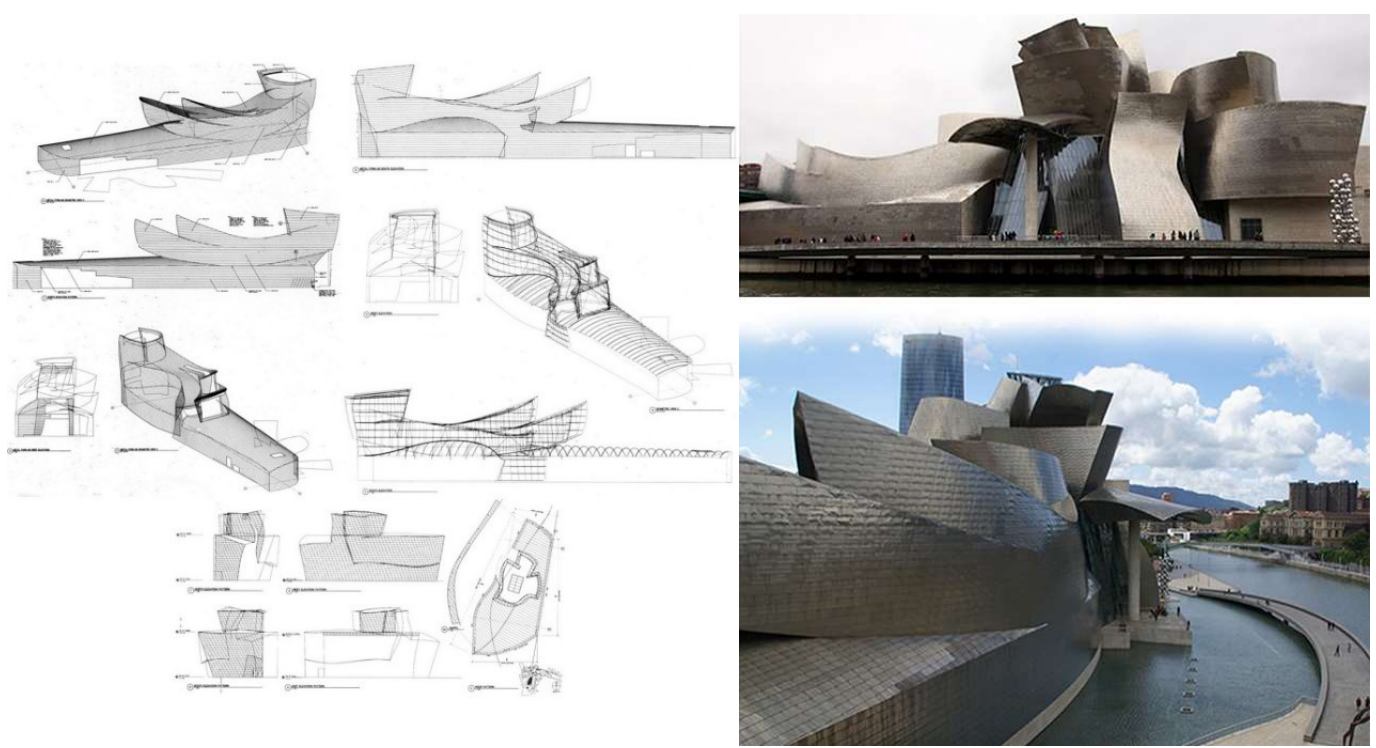

الثكل 9: متحف غو غنهايم - فر انك جيري [46]

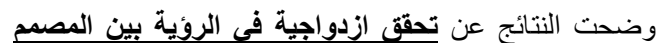

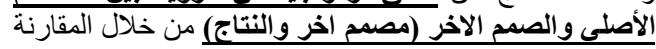

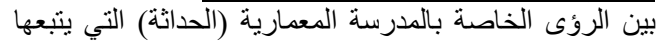

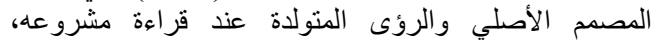

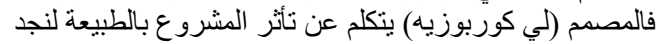

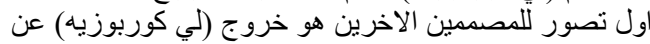

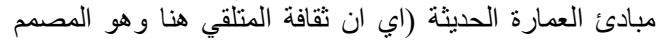
الاخر دفعته الى التصور والمقارنة ضمن الثانة المجال المعرفي

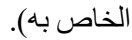

وضحت النتائج تحقق ازدواجية فى الروئية بين المصمد

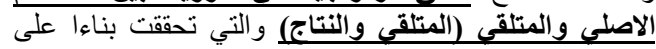

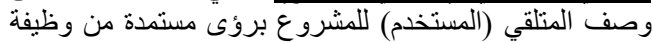

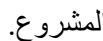

3.2

مستوى المشاريع

النتائج الخاصة بالمشروع الأول (كنبسة نوترد/م - رون

$$
\text { (رونشامب) }
$$

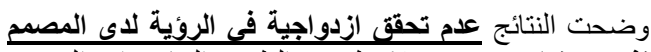

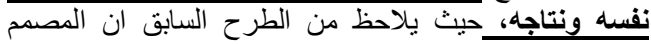

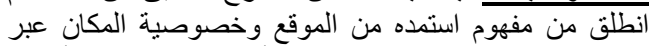

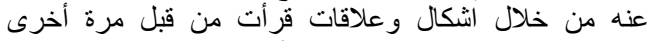
بصورة مشابهة لفكرته او مفهومه الأصلي. 


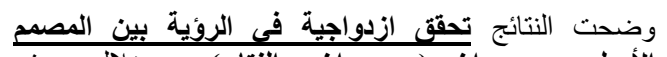

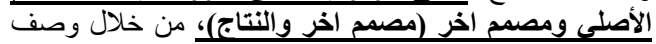

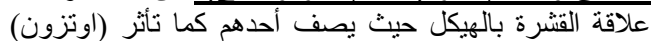

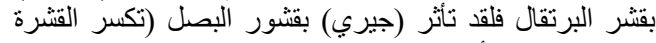

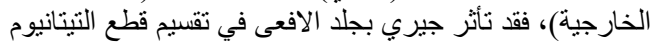
المستخدمة في التعبير الثكلي.

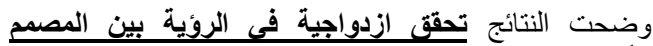

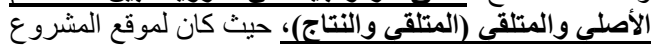

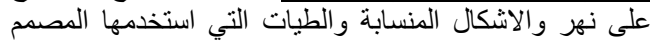

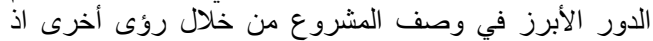

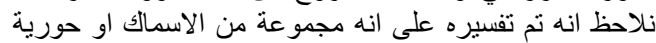

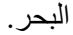

كما ويوضح الجدول (10) نتائج تحقيق الرؤية المزدوجة بناءا على تحليل

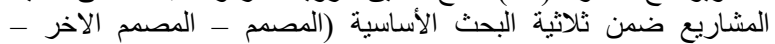
والمنلقي).
وضحت النتائج تحقق ازدواجية في الروئية بين الصمم نفسه

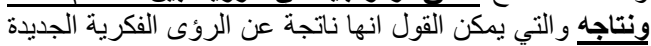

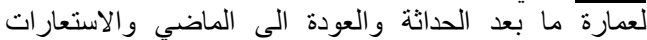

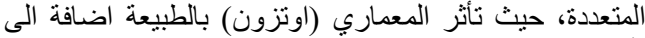
تأثره بالحضار ات القديمة واتر السياق العام للموقع.

وضحت النتائج تحقق ازدواجية في الروئية بين المصمد

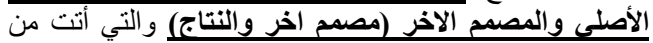

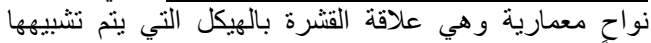

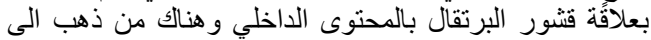

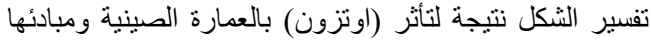

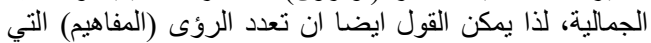

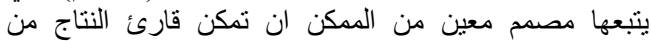
الوصول الى الرسالة او المعنى الذي ار اد المصمم ايصاله.

وضحت النتائج عدم تحقق ازدواجية فى الروئية بين المصمم

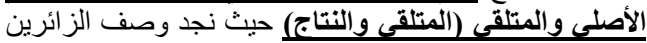

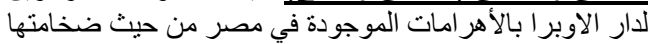

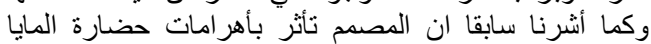

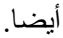

$$
\text { النتائج الخاصة بالمشروع الثالث (متحف غوغنهايج) }
$$

وضحت النتائج عدم تحقق ازدواجية في الروئية بين المصمم

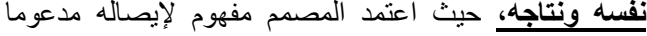
الجدول 10: نتائج تحقيق الرؤية المزدوجة بناءا على تحليل المشاريع ضمن ثلاثثية البحث الأساسية (المصمم ـ المصمم الاخر - و المتلقي) /المصدر

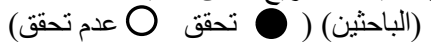

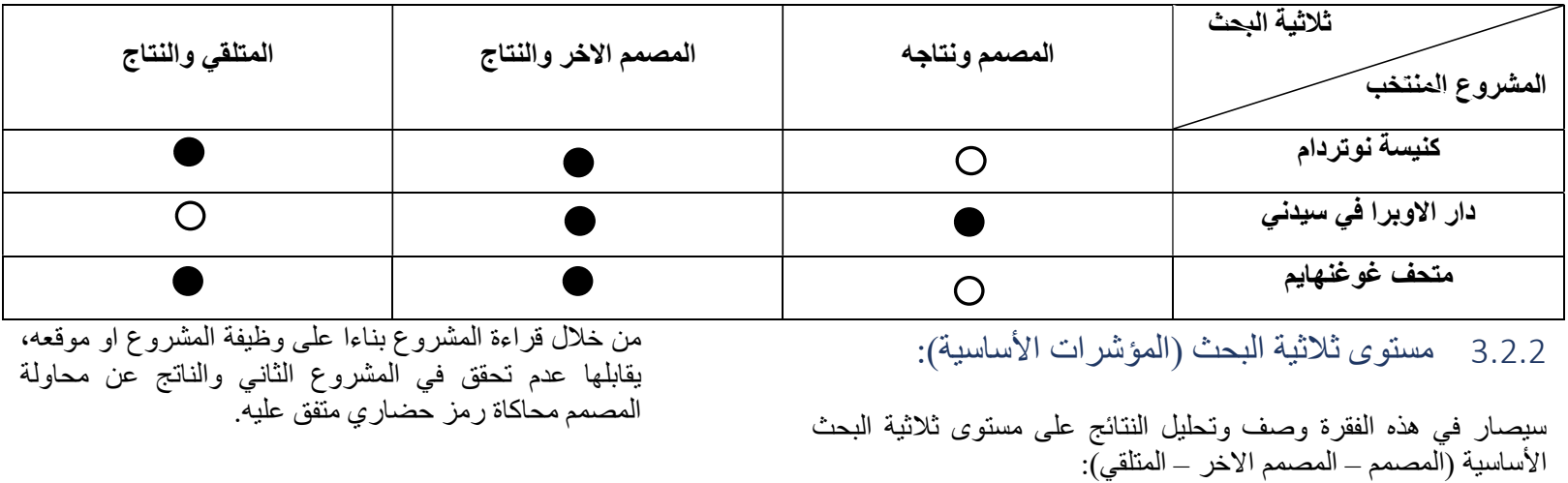

1

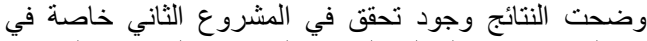

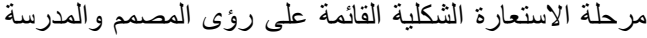

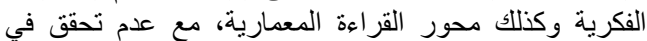

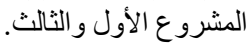

النتائج الخاصة بالمؤشر الثاني (المصمم الاخر والنتاج):

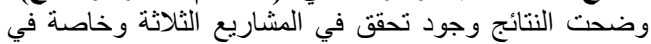

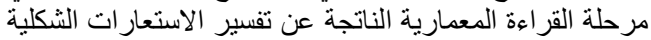

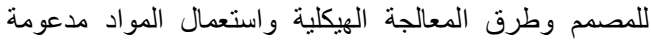

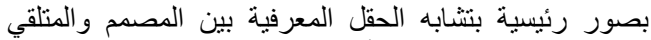

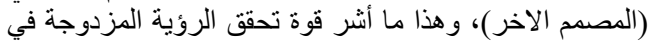
هذه الحالة بشكل اقوى من البقية.

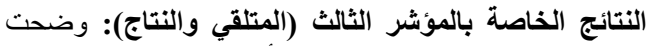




$$
\text { يوضح الجدول (11) النتائج الخاصة بالتطبيق العملي }
$$

الجدول 11: يوضح النتائج الخاصة بالتطبيق العملي /المصدر (الباحثين)

( O (

\begin{tabular}{|c|c|c|c|}
\hline \multicolumn{3}{|c|}{ اسم المشروع } & \multirow{2}{*}{ ثلاثية الأبحاثية) (المؤشرات } \\
\hline المشروع الثالث & المشروع الثاني & المشروع الاول & \\
\hline 0 & 0 & 0 & المصمم والنتاج \\
\hline 0 & 0 & 0 & المصمم الاخر والنتاج \\
\hline 0 & 0 & 0 & المتلقي و النتاج \\
\hline
\end{tabular}

رسائل او معاني تخاطب كلا المستويين، اما (الرؤية المزدوجة)

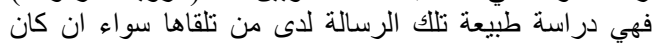

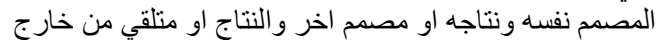
حقل العمارة والنتاج، حيث شكلت تلكك الثلاثية المؤشرات الثنات الثنات الأساسية للبحث البث

هناك وجود لتحقق ازدواجية في الرؤية بصورة جزيئة ضمن

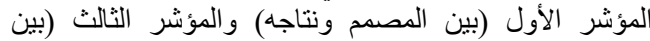

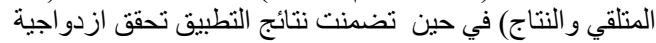

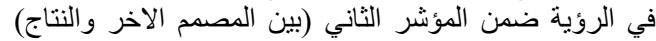

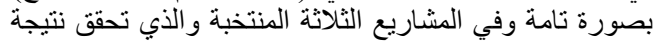

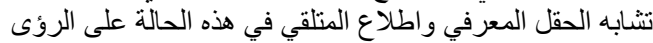

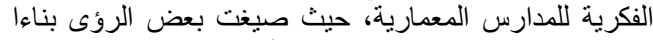

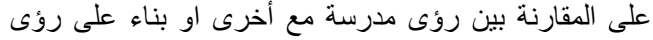

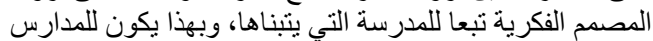

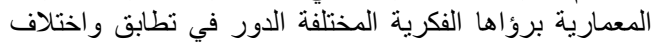

الرؤى الفكرية.

التوصيات

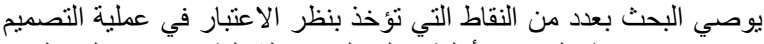

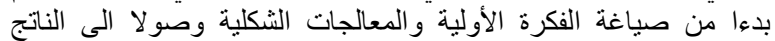

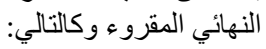

1) ضرورة الاهتمام بمفهوم الرؤية بشكل عام والرؤية المزدوجة العادية

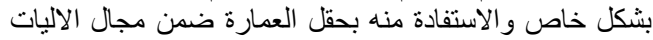
التصميمية لدى طلبة ومهندسي العمارة ومر اعاة النتائج المتحققة الآنة

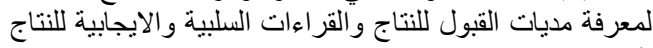

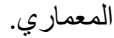

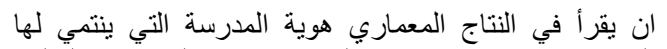

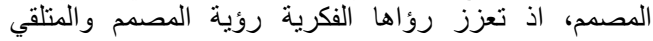

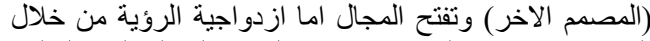

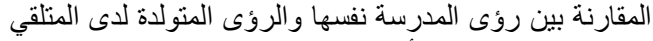

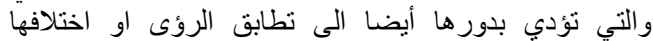

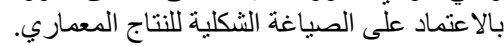

لأدوات التصميم الدور في تجسيد المصمم للفكرة او الرؤية التمبية

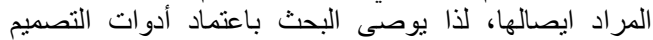

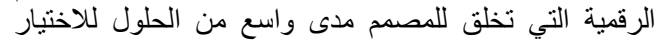

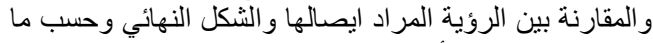
تقتضيه المنطلبات الأخرى للمشروع.

يوصي البحث بالتركيز على ترابط علاقة الرؤية المزدوجة

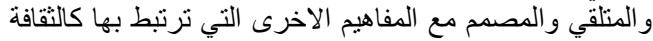

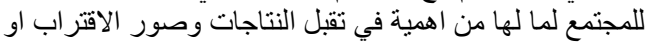

$$
\text { 3.2.3 المستوى الإجمالي }
$$

يلاحظ من الجدولين (10و11) وبناءا على ما نم التوصل اليه في تحليل

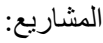

ان الرؤية المزدوجة تتحقق بصورة جزئية ضمن المؤشرين الأول (المصمم

و النتاج) والثالث (المتلقي و النتاج).

تحققت ازدواجية الرؤية بصورة كاملة بين المصمم الاخر و النتاج المعماري

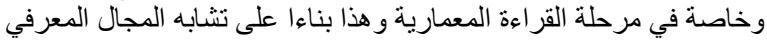

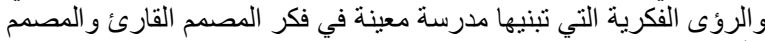
الأصلي.

3.3

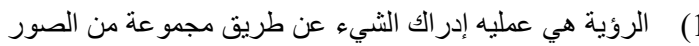

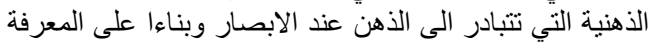

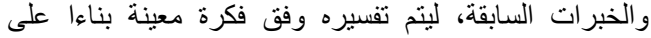

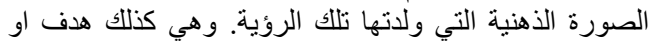

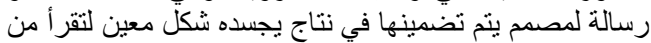

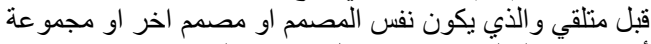

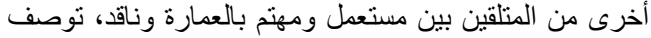

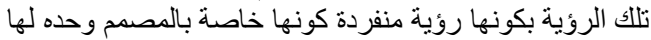

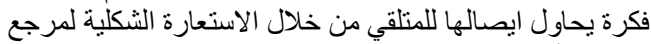

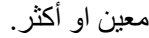

الرؤية المزدوجة هي رؤية الرسالة او المفهوم المراد ايصاله

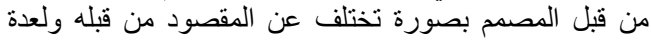

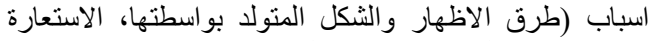

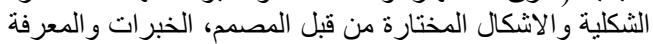

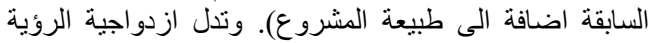

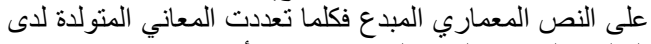

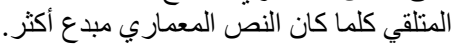

تكون الرؤية المزدوجة لدى المتلقي نفسه في تفسيره للنتاج

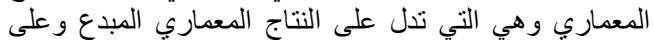

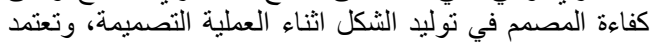

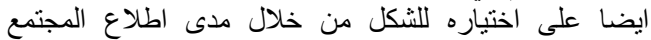

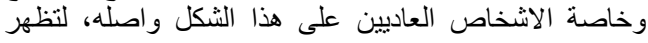
بر اعة المصمم في تجسيد الفكرة.

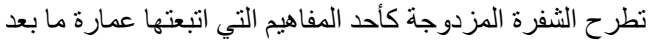

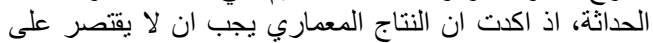

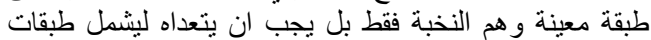
المجنمع الاخرى وذللك من خلال تضمين النتاج المعماري 
Architectural Research 238-264, 2014, PP: 242243.

[11]A. Crocker, Respecting The Vision: Sydner Opera House - a Conservation Management Plan, Sydney, N.S.W. Sydney Opera House, Australia, 2017, P: 19.

[12]A. Huxley, The Art of Seeing, Berkeley, A Creative Arts/Montana Books Publication, California, 1982, P. 28-29.

[13]A. Noe and E. Thompson, Vision and Mind: Selected Reading in the philosophy of preception, Library of Congress Cataloging-inPublication Data, USA: 2002, P. 2.

[14]A. Simitch and V. Warke, The Language of Architecture: 26 Principles Every Architect Shoud Know, Rockport Publishers, USA, 2014, PP. 18-19.

[15]B. Sweeting, "Conversing with drawings and buildings: from abstract to actual in architecture," Kybernetes, vol. 40, no. 7/8, pp. 1156-1166, 2011, P. 1163.

[16]C. A. Jencks, "'Post-Modern Architecture" From The Language of Post-Modern Architecture," Journal of the Society of Architectural Historians, pp. 306-316, 1977, P. 306.

[17] C. Chen-Yu, P. Goad and P. Myers, "The metaphorical expression of Nature in Jørn Utzon's design for the Sydney Opera House," arq: Architectural Research Quarterly, vol. 19, no. 4, pp. 381-396, 2015, PP. 381-394.

[18] C.-m. Shih, "Between Concept and Form: Learning From Case Studies," Asia Architecture and Building Engineering, vol. 3, no. 1, pp. 217221, 2004, P. 217.

[19]D. Gans, The Le Corbusier Guide, Princeton Architecture Press, New York, 1987, PP. 74-76.

[20]D. Pauly, Le Corbusier: La Chapelle de Ronchamp, The Chapel at Ronchamp, Birkhauser Verlag, Boston, 1997, P. 70.

[21]H. S. M. Coxeter, Projective Geometry, Springer-Verlag, New York, 1987, PP. 102-104.

[22]I. As and D. Schodek, Dynamic Digital Representations in Architectural: Visions in Motion, Taylor \& Francis, USA, 2008, PP. 3-4.

[23] I. Loschek, When Clothes Become Fashion: Design and Innovation Systems, Berg, New York, 2009, P. 183.

[24]I. Takahashi, Peircean Interpretation of Postmodern Architecture, PH.D. Thesis, the Office of Graduate and Professional Studies of Texas, A\&M University, Texas, UAS, 2013, PP. 47-48.

[25] J. Laurens, A. and P. Salura, "Contextual Relationship of Form and Meaning in Architectural," Journal of Applied Environmental and Biological Sciences, vol. 5, no. 12 , pp. $1-7,2015$, P. 2
الابتعاد من المراجع الفكرية والثكلية. اذ تعتبر الثقافة العامل

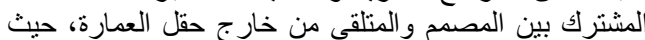

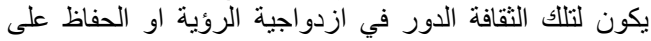

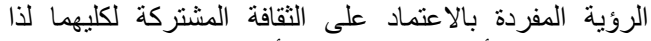

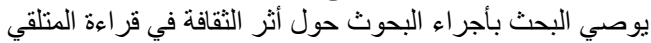

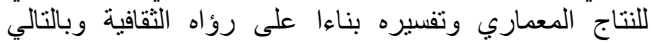

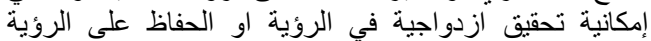

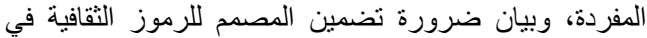

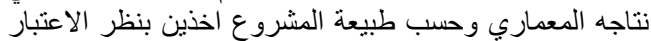
السلبية والايجابية في القراءة المتولدة.

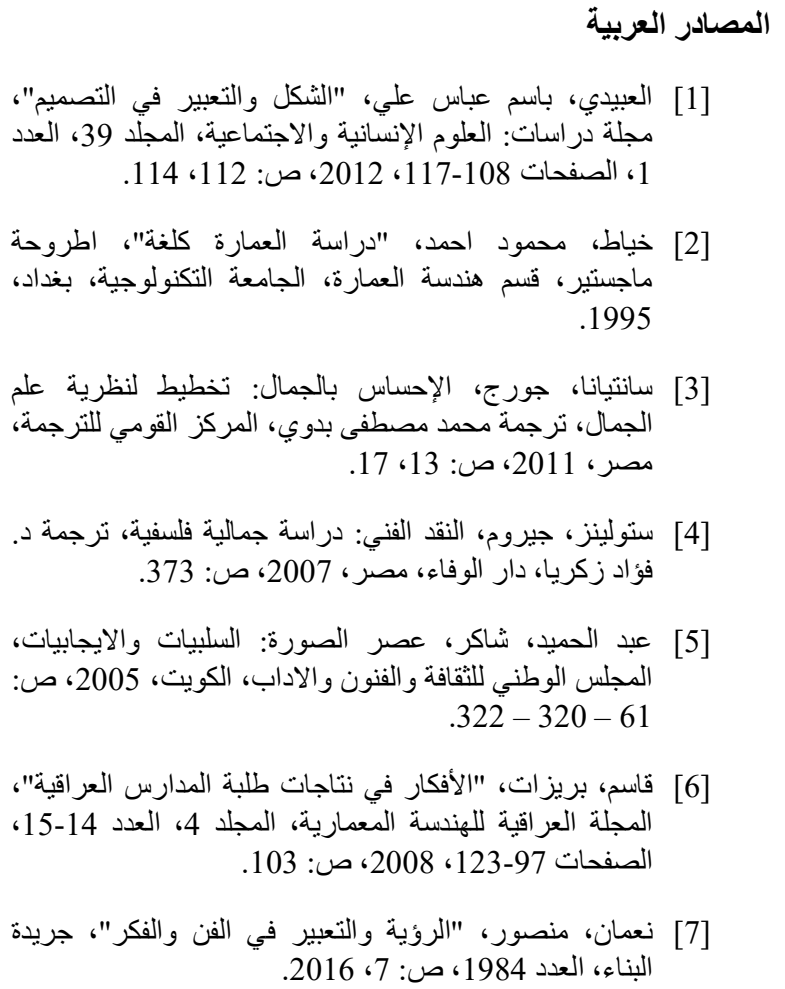

[8] A. A. Moustafa, Architectural Representation and Meaning: Towards a Theory of Interpretation, MS.c. Thesis, Department of architecture, The Massachusetts Institute of Technology, USA 1988, P: 4.

[9] A. Carter, Between Earth and Sky: The work of Jørn Utzon, as an exemplary phenomenological approach to modern architecture made concrete, In J. Baek (Ed.), Architecture and Phenomenology: Second International Architecture and Phenomenology Conference. Kyoto, Ecole francaise d'Extreme-Orient, Japan, 2009, P. 10.

[10] A. Carter, Transcultural Tectonic Connections: The Utzon Paradigm, Beyond architecture: New intersections and connections, ARCC/EAAE 2014 International Conference on 
[41]U. poerschke, Architectural Theory of Modernism: Relating Functions and Fprmsz, Routledge, New York, 2016, P. 89.

[42]W. F. Youssef, "Architecture: Perception and Concept," RG, PP. 1-11, 2014, P. 3.

$$
\text { قائمة المواقع الاكترونية }
$$

[43] A .Kroll, (2010), AD Classics: Ronchamp / Le Corbusier. Retrieved from: https://www.archdaily.com/84988/ad-classicsronchamp-le-corbusier.

[44] A. Perez, (2010), AD Classics: Sydney Opera House / Jørn Utzon. Retrieved from: https://www.archdaily.com/65218/ad-classicssydney-opera-house-j\%25c3\%25b8rn-utzon.

[45] B. Pagnotta, (2013), AD Classics: The Guggenheim Museum Bilbao / Gehry Partners. Retrieved from: https://www.archdaily.com/422470/ad-classicsthe-guggenheim-museum-bilbao-frank-gehry.

[46] B. Shapiro, (2019)m Academia. Retrieved April 28, 2019,from: https://independent.academia.edu/BruceShapiro

[47]Killick D, (2004), The Sydney Opera House. Retrieved

from:http://www.davidkillick.co.nz/writing/archi tecture/sydney-opera-house

[48] E. Stathaki, H. Green, Staff, (2007), The Guardian, Great modern buildings: Notre Dame du Haut. Retrieved from:https://www.theguardian.com/artanddesign /2007/oct/18/architecture1.

[49] M .Tyrnauer, (1997), Gehry’s October Surprise. Retrieved from:https://www.vanityfair.com/culture/1997/0 8/frank-gehry-guggenheim-museum-bil
[26] Le Corbusier , Le Corbusier talks with students, Princeton Architectural Press, New York, 1999, P. 40.

[27] L. Ribichini, Notre Dame du Haut, Ronchamp, the shape of a listening: A whole other generative hypothesis, Le Corbusier 50 years later Conference, The Polytechnic University of Valencia, Spain, PP. 1-15, 2015, PP. 4-6.

[28]L. Swanson, "Architecture, Experience and Meaning," in The World is a Text, J. Silverman and D. Rader, Eds., England, Longman, pp. 193202, 2011, P. 196.

[29] N. Amiri, "Modernism and Postmodernism in Architecture, An Emphasis on The Characteristics, Similarities and Differences," The Turkish Online Journal of Design, Art and Communication - TOJDAC, Special Edition, pp. 1629-1634, 2016, PP. 1628-1631.

[30]N. Elleh, Reading the architecture of the underprivileged classes, $1^{\text {st }}$ ed., Ashgate Publishing Company, USA, 2014, P. 18.

[31]N. Sala, "Complexity in architecture: a small scale analysis," in Design and nature II, M. W. Collins and C. A. Brebbia , Eds., WIT Press / Computational Mechanics; illustrated edition, UK, PP. 36-44, 2004, p. 39.

[32] P. Goldberger, Building Art: The Life and Work of Frank Gery, Alfred A. Knopf, USA, 2015, P. 301.

[33]P. Johnson and M. Wigley, Deconstructivist architecture, The Museum of Modern Art, New York, 1988, P. 11.

[34]R. Alihodžić and N. Kurtović-Folić, "Phenomenology of Perception and Memorizing Contemporary Architectural Forms," Architecture and Civil Engineering, vol. 8, no. $\mathrm{N}^{0} 4$, pp. 425-439, 2010, PP. 430-431.

[35]R. Weston, Utzon: Inspiration, Vision, Architecture, Hellerup, Denmark: Edition Blondal, 2002, P. 164.

[36] S. Best and D. Kellner, The Postmodern Turn, The Guilford Press, New York,1997, P. 138139.

[37] S. D. Bleeckere and S. Gerards, Narrative Architecture: A Designer's Story, Routledge, New York, 2017, P. 48.

[38] S. Kutucu, The concept of heteorogeneity and Hetero-architecture in the context of plurality in the postmodern age, Ms.c. Thesis, the Graduate School of Izmir, Institute of Technology, Urla, Turkey, 1998, P. 43.

[39] S. S. Vučković, "Architectural Communication: Intra and Extra activity of Architecture," Spatium international review, vol. 7201, no. 29, pp. 68-74, 2013, P. 68.

[40] S. Y. Islami, The Architecture Of Surface: The Significance of Surficial Thought and Topological Metaphors of Design, PHD. Thesis, Department of Architecture, University of Edinburgh, Scotlsnd, 2009, PP. 228-238-239. 


\title{
Double Vision in Architecture
}

\author{
Ahmed Hashim Al-Eqapy ${ }^{1}$, Basim H. Hashim Al-Majidi ${ }^{2}$, and Noor Ameer Al-Shukri ${ }^{3}$, \\ ${ }^{1}$ Department of Architectural Engineering, University of Technology, Baghdad, Iraq, 90047@uotechnology.edu.iq \\ 2Department of Architectural Engineering, University of Technology, Baghdad, Iraq, 90004@uotechnology.edu.iq \\ ${ }^{3}$ National Center for Engineering Consultancy, Ministry of Construction and Housing and Municipalities, Baghdad, Iraq, \\ 90103@student.uotechnology.edu.iq \\ *Corresponding author: Noor Ameer Al-Shukri,90103@student.uotechnology.edu.iq
}

Published online: 31 December 2020

Abstract - The architecture and its outputs are one of the most relevant fields of knowledge with human beings and their daily life, and the fact that the architectural product represents the architectural vision that which is trying to deliver to the society through the architectural images of various projects, which should be perceived by the eye and trying to interpret them, so the research aims to study the vision generated by the recipient, whether the vision of the designer himself when he sees his work as an architect, another designer acting as a critic, or those who are outside of architecture field, and how that vision that the designer wants to deliver can be transformed from single vision to a double vision about the architectural product. The problem of research was the lack of clear knowledge about the role of different intellectual visions of architectural schools in the compatibility and differing visions between the designer and the other designer or the designer and the recipient to produce a double vision in architecture. The research deals with the concept of vision in general in order to extraction a set of concepts that link the vision with the architecture, whether single or double, which can be reflected by the following elements: (the concept intended by the designer - the form and its treatments - the architectural reading). In other words, it starts with the designer vision or concept and depends on what he wants to deliver, and this leads the research to study the sources of ideas and architectural images which reflect the vision of the designer, which depends mainly on architectural schools and their role in the formulation of the designer thought, and then this will be applied to elected architectural projects belonging to different schools to reach that there is a strong duplication of vision between the other designer and the product versus a partial duplication of vision between the designer and the product and between the recipient and the product.

Keywords - Vision, Double vision, Architectural images, Reading, The designer thought. 